NBER WORKING PAPER SERIES

\title{
MONETARY POLICY AND BUSINESS CYCLES WITH ENDOGENOUS ENTRY AND PRODUCT VARIETY
}

\author{
Florin O. Bilbiie \\ Fabio Ghironi \\ Marc J. Melitz \\ Working Paper 13199 \\ http://www.nber.org/papers/w13199
NATIONAL BUREAU OF ECONOMIC RESEARCH
1050 Massachusetts Avenue
Cambridge, MA 02138
June 2007

For helpful comments, we thank Daron Acemoglu, Virgiliu Midrigan, Gernot Müller, Julio Rotemberg, Michael Woodford, and participants in the Twenty-second NBER Annual Conference on Macroeconomics, the Thirty-eighth Konstanz Seminar on Monetary Theory and Policy, and a seminar at Boston College. We are grateful to Massimo Giovannini, Margarita Rubio, and Frank Virga for excellent research assistance. Remaining errors are our responsibility. Bilbiie thanks the NBER for hospitality as a Visiting Fellow while this paper was written. Ghironi and Melitz thank the NSF for financial support through a grant to the NBER. The views expressed herein are those of the author(s) and do not necessarily reflect the views of the National Bureau of Economic Research.

(C) 2007 by Florin O. Bilbiie, Fabio Ghironi, and Marc J. Melitz. All rights reserved. Short sections of text, not to exceed two paragraphs, may be quoted without explicit permission provided that full credit, including $(\subset$ notice, is given to the source. 
Monetary Policy and Business Cycles with Endogenous Entry and Product Variety

Florin O. Bilbiie, Fabio Ghironi, and Marc J. Melitz

NBER Working Paper No. 13199

June 2007

JEL No. E31,E32,E52

\begin{abstract}
$\underline{\text { ABSTRACT }}$
This paper studies the role of endogenous producer entry and product creation for monetary policy analysis and business cycle dynamics in a general equilibrium model with imperfect price adjustment. Optimal monetary policy stabilizes product prices, but lets the consumer price index vary to accommodate changes in the number of available products. The free entry condition links the price of equity (the value of products) with marginal cost and markups, and hence with inflation dynamics. No-arbitrage between bonds and equity links the expected return on shares, and thus the financing of product creation, with the return on bonds, affected by monetary policy via interest rate setting. This new channel of monetary policy transmission through asset prices restores the Taylor Principle in the presence of capital accumulation (in the form of new production lines) and forward-looking interest rate setting, unlike in models with traditional physical capital. We also study the implications of endogenous variety for the New Keynesian Phillips curve and business cycle dynamics more generally, and we document the effects of technology, deregulation, and monetary policy shocks, as well as the second moment properties of our model, by means of numerical examples.

Florin O. Bilbiie

University of Oxford

Nuffield College

Oxford OX1 1NF

UK

florin.bilbiie@nuffield.ox.ac.uk

Fabio Ghironi

Boston College

Department of Economics

140 Commonwealth Avenue

Chestnut Hill, MA 02467-3859

and NBER

fabio.ghironi@bc.edu

Marc J. Melitz

Dept of Economics \& Woodrow Wilson School

Princeton University

308 Fisher Hall

Princeton, NJ 08544

and NBER

mmelitz@princeton.edu
\end{abstract}




\section{Introduction}

Since the mid 1980s, a large body of literature has developed in which monetary policy is analyzed in microfounded, dynamic, stochastic, general equilibrium (DSGE) models of the business cycle with monopolistic competition and nominal rigidity. The importance of this 'New Keynesian' literature (summarized, for instance, by Woodford, 2003) for policymaking is evidenced by the current use of such models by many central banks or international institutions as input for policy decisions. ${ }^{1}$ Most of this literature, however, relies on monopolistic competition merely as a vehicle to introduce price (or wage) setting power and then assume that price (or wage) setting is not frictionless, resulting in nominal rigidity and a role for monetary policy. The overwhelming majority of models abstracts from producer entry mechanisms and assumes a constant number of producers. The joint assumptions of monopolistic competition and no entry raise both theoretical and empirical questions. First, absent either properly designed markup-offsetting subsidies or increasing returns of appropriate degree, monopolistic competition in these models results in permanent (i.e., steadystate) positive profits, casting doubts on the theoretical appeal of the zero-entry assumption. ${ }^{2}$ Furthermore, recent empirical evidence for the U.S. has substantiated the endogenous fluctuations in the number of producers and the range of available goods that take place over the typical length of a business cycle. A previous literature documented the strong procyclical behavior of net producer entry (measured either as incorporated firms or as production establishments). ${ }^{3}$ Bernard, Redding, and Schott (2006) document how existing U.S. manufacturing establishments devote a substantial portion of their production to goods that they did not previously produce. For U.S. aggregate manufacturing, the value of new goods produced represents just under $10 \%$ of annual manufacturing output. ${ }^{4}$ Axarloglou (2003) and Broda and Weinstein (2007) directly measure the introduction of new varieties in the U.S. economy and document a strong correlation with the business cycle. Across a wide sample of U.S. consumer purchases, Broda and Weinstein (2007) document that a $1 \%$ increase in aggregate sales is associated with a $0.35 \%$ increase in the sales of

\footnotetext{
${ }^{1}$ See, for instance, the IMF's GEM model (illustrated by Laxton and Pesenti, 2003, among others) and the Federal Reserve Board's SIGMA model (illustrated by Erceg, Guerrieri, and Gust, 2005, among others).

${ }^{2}$ Rotemberg and Woodford (1995) addressed the implausibility of positive steady-state profits by assuming increasing returns to scale induced by fixed, per-period costs. However, under this assumption, any shock that causes profits to fall below zero should generate exit and induce a non-linearity in firm decisions.

${ }^{3}$ See Campbell (1998), Chatterjee and Cooper (1993), and Devereux, Head, and Lapham (1996a,b). We illustrate similar evidence in Bilbiie, Ghironi, and Melitz (2005).

${ }^{4}$ Bernard, Redding, and Schott (2006) measure new goods at a relatively coarse level of disaggregation: a 5-digit U.S. SIC code. Contributions of product creation at a more disaggregated level would be substantially higher. See Bilbiie, Ghironi, and Melitz (2005) for further details.
} 
newly introduced products in that quarter. ${ }^{5}$ These theoretical and empirical observations suggest that there is scope for introducing producer entry and product creation in models with monopolistic competition and imperfect price adjustment, and studying the consequences of endogenous product variety for business cycle propagation and policy in these models.

This paper takes an initial step in this direction by re-introducing the endogenous link between product creation (firm entry) and monopolistic competition in a DSGE model with imperfect price adjustment. We explore the positive and normative consequences of endogenous producer entry and product variety over the business cycle by introducing nominal rigidity into the flexible price model developed by Bilbiie, Ghironi, and Melitz (2005 - henceforth, BGM). We incorporate nominal rigidity in a standard form often used in the recent New Keynesian literature - a quadratic cost of price adjustment as in Rotemberg (1982). ${ }^{6}$ The endogenous response of producer entry - product creation subject to sunk entry costs - over the business cycle provides a key new transmission mechanism in our model. This producer entry, in general equilibrium, is tied to the household saving decisions via the purchase of share holdings in the portfolio of firms that operate in the economy. ${ }^{7}$ In BGM, we show that such a model, under flexible prices, performs similarly to the standard real business cycle (RBC) model concerning the cyclicality of key U.S. macroeconomic aggregates that are traditionally the subject of RBC studies. However, this model can additionally explain many other important empirical patterns over the business cycle, such as the procyclicality of firm entry and profits, and - with non-C.E.S. preferences - the countercyclicality of markups. Significantly, these countercyclical markups are induced while still preserving the procyclicality of profits (due to the response of producer entry) - a well known challenge for the benchmark New Keynesian model with sticky prices. ${ }^{8}$

\footnotetext{
${ }^{5}$ Although the level of product substitutability can be very high in the Broda and Weinstein (2007) sample, their evidence suggests that product creation is concentrated in product categories that are much more differentiated (non-food products).

${ }^{6}$ We choose the Rotemberg model over the familiar Calvo (1983)-Yun (1996) setup to avoid heterogeneity in prices within and across cohorts of price setters that entered at different dates. Earlier flexible-price, business cycle models with monopolistic competition and endogenous entry include also Ambler and Cardia (1998) and Cook (2001). Comin and Gertler (2006), Jaimovich (2004), Jovanovic (2006), and Stebunovs (2006) are more recent contributions to the theoretical literature. See BGM for a discussion of the relation with our model.

${ }^{7}$ There is a one-to-one mapping between a product, a producer, and a firm in our model. For consistency with the recent literature, we routinely use the word firm to refer to an individual unit of production. The latter is best thought of as a production line associated with a specific good. These goods can potentially be introduced within incumbent firms, where product managers independently make profit maximizing decisions for their production lines. Our model thus does not address the boundaries of the firm.

${ }^{8}$ When we augment the model to include physical capital in production of existing goods and creation of new production lines, the model does better than the standard RBC framework at matching volatility and persistence of U.S. GDP. However, a high rate of capital depreciation is required for the model to have a unique, non-explosive solution.
} 
The introduction of endogenous product variety in a sticky-price model of the business cycle allows us to address issues that are absent in existing, fixed-variety models, as well as to qualify some of the results of those models in the presence of this new margin. To start with, the consumer price index coincides with the price of each individual product in the symmetric equilibrium of one-sector, fixed-variety models. In a model with endogenous variety, a meaningful distinction between the consumer price index and the average product price arises because the welfare-relevant consumer price index varies with the number of varieties (it is cheaper to satisfy a given level of demand with more varieties) for given product price level. Otherwise put, the price of each good relative to the consumption basket increases with the number of varieties - the marginal benefit from consuming the bundle is thus higher relative to the marginal benefit of any unit of an individual good, making consumption of the basket more desirable. We show that, when price rigidity concerns price setting for individual goods, optimal policy should stabilize product prices (the average price of output, often referred to as producer price below) rather than the welfare-consistent consumer price index. ${ }^{9}$

Our framework also suggest a new motive for price stability as a desirable policy prescription. Since, as in Rotemberg (1982), price adjustment costs are deducted from firm profits, and these costs are proportional to (squared) producer price inflation, the latter acts as a distortionary tax on firm profits in our model. This tax distorts the allocation of resources to product creation (versus production of existing varieties) and induces a suboptimal amount of product variety in each period. This is an intuitive explanation for why the central bank should pursue producer price stability in our model, and an extra argument for price stability absent from fixed-variety models.

Turning to implications that qualify results from fixed-variety models, but remaining in the area of policy prescriptions, it is by now conventional wisdom from the benchmark fixed-variety model without physical capital that the central bank should follow what has become known as the Taylor Principle. This policy prescription requires that the central bank be 'active,' in the sense of increasing the nominal interest rate more than one-to-one in response to increases in inflation. ${ }^{10}$ Perhaps surprisingly, however, the introduction of physical capital in the fixed-variety model changes this prescription dramatically, as shown by Dupor (2001) in a continuous-time

\footnotetext{
${ }^{9}$ The issue of what inflation rate should be targeted by policy is also related to an empirically relevant measurement problem that occurs because CPI data do not account for the introduction of new goods in the welfare-consistent manner prescribed by the model. As a consequence, the observed CPI is a biased measure of the welfare-based cost-of-living index, as documented by a recent and growing literature - see e.g. Broda and Weinstein (2006). Broda (2004) argues that the central bank should stabilize CPI inflation. This is not inconsistent with the prescription of our model if measured CPI inflation is closer to average product price inflation than to welfare-based consumer price inflation.

${ }^{10}$ Kerr and King (1996) and Clarida, Galí, and Gertler (2000) were the first to derive this result in the now standard New Keynesian framework. Leeper (1991) has a related discussion.
} 
model and further developed by Carlstrom and Fuerst (2005) in discrete time and in the presence of adjustment costs. Dupor shows that 'passive' interest rate setting (a less than proportional response to inflation) is necessary and sufficient for local determinacy and stability, while Carlstrom and Fuerst conclude that it is essentially impossible to achieve determinacy with forward-looking interest rate setting. In contrast to these results, the Taylor Principle holds in our economy in which capital accumulation takes the form of creating new production lines, regardless of whether the monetary authority responds to expected or current product price inflation. ${ }^{11}$

The Taylor Principle is restored with our form of capital accumulation precisely because our framework features an endogenous price of capital that plays a crucial role in monetary policy transmission. Indeed, we show that free entry implies that the price of equity shares (the value of the firm) appears in the New Keynesian Phillips curve that governs the dynamics of inflation. Moreover, a no-arbitrage condition links the real return on bonds (which the central bank affects by setting the nominal interest rate) to the real return on equity - the ratio of next period's dividends and share price to the current price of equity. This identifies a novel channel of monetary policy transmission that links interest rate setting to equity prices and, through free entry and the Phillips curve, inflation. In a nutshell, a temporary interest rate cut reduces the real return on bonds, inducing the expected return on equity to fall and the household to consume more today. The decrease in the expected return from investing in product creation is brought about by an increase in today's price of equity (the value of the firm) relative to tomorrow's. The price of equity (the value of the firm) is related to marginal cost (the ratio of the real wage to labor productivity) by the free entry condition in our model. Marginal cost rises, inducing a fall in the markup and, by the Phillips curve, an increase in inflation. This transmission of monetary policy through the price of equity is absent in standard, fixed-variety models even when those models do feature an endogenous price of capital due to adjustment costs (see Carlstrom and Fuerst, 2005).

Further implications of explicitly modeling endogenous product creation pertain to inflation and markup dynamics. As in the standard fixed-variety model, a New Keynesian Phillips curve relating producer price inflation to its expected value and the current markup holds in our model. However, endogenous product creation has important consequences for empirical exercises that estimate Phillips curves. First, in the presence of endogenous variety, the markup is not simply the inverse of the labor share of income, as in Sbordone (2002) or Galí and Gertler (1999). In

\footnotetext{
${ }^{11}$ The same holds for welfare-consistent CPI inflation, subject to the caveat implied by our normative analysis that monetary policy should not target welfare-consistent consumer prices in our model.
} 
our model, the markup can be expressed as the inverse of a labor share in consumption output, controlling for labor used to set up new production lines (labor that is 'overhead' from an aggregate perspective). A close proxy for this labor share has been estimated by Rotemberg and Woodford (1999), and it is the relevant variable that should be used to estimate the Phillips curve in the presence of endogenous variety. ${ }^{12}$ We propose an alternative proxy for the markup based on the inverse of the share of profits in consumption, which is 'model-free,' in the sense that it could be used regardless of one's stand on product creation. Furthermore, we identify an 'endogeneity bias' in the identification of what the literature commonly labels 'cost-push shocks' (see e.g. Clarida, Galí, and Gertler, 1999): In the presence of endogenous variety, the Phillips curve features an extra term that depends on the number of available varieties. This term would be attributed to cost-push shocks by a researcher using a markup proxy that does not account for variety when estimating the Phillips curve. Finally, it has been pointed out that one of the main drawbacks of the forward-looking New Keynesian Phillips curve is its failure to generate endogenous inflation persistence (see e.g. Fuhrer and Moore, 1995). We show that our version of the Phillips curve can potentially alleviate this problem, because the number of varieties featured in the Phillips curve is a state variable, and hence it induces extra persistence in inflation.

Numerical examples show that the responses to aggregate productivity and deregulation shocks under simple, but plausible specifications of interest rate setting are close to the flexible-price responses. Exogenous interest rate cuts induce the economy to expand, but reduce entry because the associated increase in real wages increases the cost of firm creation and the expected return from investing in new products falls. With productivity shocks as the source of fluctuations and an empirically plausible, simple rule for interest rate setting involving interest rate smoothing and a response to expected producer price inflation, the cyclical properties of endogenous variables are very close to those of the flexible-price counterpart and, in turn, to those of the benchmark RBC model, as documented by BGM. In contrast to the flexible-price model with translog preferences studied in BGM, sticky prices with C.E.S. preferences yield too much markup countercyclicality and a counterfactual time profile of this cyclicality. This happens because the markup is no longer tied to the number of producers as in BGM with translog preferences. On the bright side, aggregate profits remain procyclical (consistent with stylized facts) even in the presence of a very countercyclical markup, and the model remains able to explain the procyclicality of business creation.

\footnotetext{
${ }^{12}$ Sbordone (2002) showed that using this corrected measure does not affect the estimates obtained when using the baseline markup proxy. Our framework suggests a specific calibration scheme for the share of overhead labor used in this correction, based on the share of labor used for creating new products.
} 
Producer entry and product creation pose an interesting question for the modeling of nominal rigidity. When a new entrant makes its first price setting decision, we must take a stand on whether it operates as all pre-existing producers do, subject to the same nominal rigidity - thus preserving the symmetry across producers that is a feature of the Rotemberg (1982) model -, or whether it sets its price in flexible fashion, but knowing that it will face a cost of adjusting its price in all subsequent periods. We begin our analysis by assuming that new entrants inherit the same price rigidity as pre-existing firms. This considerably simplifies the model and allows us to obtain an initial set of analytical and numerical results. We then turn to the model in which new entrants set prices in flexible fashion, but knowing that they will be subject to a cost of price adjustment from the following period on. ${ }^{13}$ In this case, nominal rigidity results in heterogeneity in price levels across cohorts of producers that entered the economy at different points in time, and the aggregate degree of nominal rigidity is endogenous: Expansions are associated with lower aggregate rigidity because the number of new entrants whose decision is not influenced by past price setting increases. We show that the log-linear version of this extended model can still be solved in tractable fashion, and we explore the consequences of endogeneity in aggregate rigidity by means of numerical examples. Plausible parameter values imply responses to shocks that are virtually indistinguishable from those of the benchmark model. Since we assume that average product turnover is realistically small at quarterly frequency, small changes in the fraction of firms that set prices in more flexible fashion triggered by shocks have negligible aggregate consequences, and the benchmark model in which new entrants inherit the same price adjustment cost as incumbents yields robust conclusions.

As in BGM, we explore the consequences of non-C.E.S. preferences by replacing the familiar Dixit-Stiglitz (1977) variety aggregator with a general, homothetic specification of symmetric preferences - parametrized in translog form for model solution purposes. This implies that the elasticity of substitution across products increases with the number of producers, introducing an additional effect of the number of available goods on inflation in the New Keynesian Phillips curve. In our numerical examples, this extension yields conclusions that are similar to those of the benchmark model, although it further improves the performance of the model on the inflation persistence front.

Lewis (2006) and Elkhoury and Mancini Griffoli (2006) develop models with nominal rigidity that are closest to the one studied here. Lewis introduces monopoly power in the labor market and sticky wages in familiar Calvo (1983)-Yun (1996) fashion into the BGM model. She documents

\footnotetext{
${ }^{13}$ For completeness of comparison, we also consider a version of the model in which new price setters simply set their initial price as a constant markup over marginal cost.
} 
VAR evidence that monetary policy expansions result in increased firm entry by boosting aggregate demand, and she shows that the sticky-wage model reproduces this evidence. Elkhoury and Mancini Griffoli assume that entry costs in the BGM model take the form of fees paid to lawyers with monopoly power. Under nominal rigidity, the lawyers set the entry fees in Calvo-Yun fashion and, as in Lewis, a monetary expansion that boosts the economy results in increased firm entry. Monetary policy expansions boost firm entry in these models because they induce the real cost of product creation to fall. ${ }^{14}$ Bergin and Corsetti (2005) document VAR evidence on the consequences of exogenous changes in monetary policy for entry similar to that in Lewis' paper. They set up a model with entry and one-period price rigidity that replicates this evidence, and they characterize optimal monetary policy and the properties of shock transmission. In Bergin and Corsetti's model, monetary expansions induce increased firm entry by increasing discounted expected future profits. We show that a version of our model in which entry requires purchases of materials rather than hiring labor generates increased entry in response to monetary policy shocks by removing the tight connection between marginal production cost and the value of the firm embedded in the benchmark setup. Berentsen and Waller (2007) contribute to this literature on monetary policy with firm entry by introducing endogenous seller entry subject to an entry fee in Lagos and Wright's (2005) model, in which informational frictions motivate the existence of money as a medium of exchange. Price posting in advance of entry constitutes a price rigidity similar to Bergin and Corsetti's in their model. They show that the Friedman rule (zero nominal interest rate) is optimal in their model with fixed entry costs. But departures from the Friedman rule are optimal when congestion effects cause entry costs to increase with the number of firms.

The rest of the paper is organized as follows. Section 2 presents our benchmark model. Section 3 obtains the results on optimal monetary policy in the benchmark setup. Section 4 discusses the implications of endogenous entry and product variety for the New Keynesian Phillips curve. Section 5 studies monetary policy through interest rate setting in our model. Section 6 illustrates the business cycle properties of the model. Section 7 discusses the main results of the extensions we explore: the assumption that entry requires materials rather than labor, the alternative assumptions on initial price setting by new entrants, and non-C.E.S. preferences. Section 8 concludes.

\footnotetext{
${ }^{14}$ The models in Lewis (2006) and Elkhoury and Mancini Griffoli (2006) are in principle subject to one of the problems that our approach aims to address: They rely on monopoly power as a stepping stone for nominal rigidity, but they abstract from entry (by workers or lawyers) in the presence of monopoly profits.
} 


\section{The Model}

\section{Household Preferences and the Intratemporal Consumption Choice}

We consider a cashless economy as in Woodford (2003). The economy is populated by a unit mass of atomistic, identical households. The representative household supplies $L_{t}$ hours of work in each period $t$ in a competitive labor market for the nominal wage rate $W_{t}$ and maximizes expected intertemporal utility $E_{t}\left[\sum_{s=t}^{\infty} \beta^{s-t} U\left(C_{s}, L_{s}\right)\right]$, where $C_{t}$ is consumption and $\beta \in(0,1)$ the subjective discount factor. The period utility function takes the form $U\left(C_{t}, L_{t}\right)=\ln C_{t}-$ $\chi\left(L_{t}\right)^{1+1 / \varphi} /(1+1 / \varphi), \chi>0$, where $\varphi \geq 0$ is the Frisch elasticity of labor supply to wages, and the intertemporal elasticity of substitution in labor supply.

At time $t$, the household consumes the basket of goods $C_{t}$, defined over a continuum of goods $\Omega$ : $C_{t}=\left(\int_{\omega \in \Omega} c_{t}(\omega)^{\theta-1 / \theta} d \omega\right)^{\theta /(\theta-1)}$, where $\theta>1$ is the symmetric elasticity of substitution across goods. At any given time $t$, only a subset of goods $\Omega_{t} \subset \Omega$ is available. Let $p_{t}(\omega)$ denote the nominal price of a good $\omega \in \Omega_{t}$. The consumption-based price index for the home economy is then $P_{t}=\left(\int_{\omega \in \Omega_{t}} p_{t}(\omega)^{1-\theta} d \omega\right)^{1 /(1-\theta)}$, and the household's demand for each individual good $\omega$ is $c_{t}(\omega)=\left(p_{t}(\omega) / P_{t}\right)^{-\theta} C_{t}$.

\section{Firms}

There is a continuum of monopolistically competitive firms, each producing a different variety $\omega \in \Omega$. Production requires only one factor, labor. Aggregate labor productivity is indexed by $Z_{t}$, which represents the effectiveness of one unit of labor. Productivity is exogenous and follows an $A R(1)$ process in percent deviation from its steady-state level. Output supplied by firm $\omega$ is $y_{t}(\omega)=Z_{t} l_{t}(\omega)$, where $l_{t}(\omega)$ is the firm's labor demand for productive purposes. The unit cost of production, in units of the consumption good $C_{t}$, is $w_{t} / Z_{t}$, where $w_{t} \equiv W_{t} / P_{t}$ is the real wage.

Prior to entry, firms face a sunk entry cost of $f_{E, t}$ effective labor units, equal to $w_{t} f_{E, t} / Z_{t}$ units of the consumption good. There are no fixed production costs. Hence, all firms that enter the economy produce in every period, until they are hit with a "death" shock, which occurs with probability $\delta \in(0,1)$ in every period. We assume that the entry cost $f_{E, t}$ is exogenous and treat changes in $f_{E, t}$ as changes in market regulation.

Firms face nominal rigidity in the form of a quadratic cost of adjusting prices over time (Rotemberg, 1982). Specifically, the real cost (in units of the composite basket) of output-price inflation 
volatility around a steady-state level of inflation equal to 0 facing firm $\omega$ is:

$$
\operatorname{pac}_{t}(\omega) \equiv \frac{\kappa}{2}\left(\frac{p_{t}(\omega)}{p_{t-1}(\omega)}-1\right)^{2} \frac{p_{t}(\omega)}{P_{t}} y_{t}^{D}(\omega), \quad \kappa \geq 0
$$

This expression is interpreted as the amount of marketing materials that the firm must purchase when implementing a price change. We assume that this basket has the same composition as the consumption basket. The cost of adjusting prices is proportional to the real revenue from output sales, $\left(p_{t}(\omega) / P_{t}\right) y_{t}^{D}(\omega)$, where $y_{t}^{D}(\omega)$ is firm $\omega$ 's output demand.

Firms face demand for their output from consumers and firms themselves when they change prices. In each period, there is a mass $N_{t}$ of firms producing and setting prices in the economy. When a new firm sets the price of its output for the first time, we appeal to symmetry across firms and interpret the $t-1$ price in the expression of the price adjustment cost for that firm as the notional price that the firm would have set at time $t-1$ if it had been producing in that period. An intuition for this simplifying assumption is that all firms (even those that are setting the price for the first time) must buy the bundle of goods $\operatorname{pac}_{t}(\omega)$ when implementing a price decision. ${ }^{15}$ It should be noted, however, that this assumption is entirely consistent both with the original Rotemberg (1982) setup and with our timing assumption below. Specifically, new entrants behave as the (constant number of) price-setters do in Rotemberg's framework, where an initial condition for the individual price is dictated by nature. In our framework, new entrants at any time $t$ who start producing and setting prices at $t+1$ are subject to precisely the same assumption as price setters in Rotemberg's original setup. Moreover, the assumption that a new entrant, at the time of its first price setting decision, knows the average product price last period is consistent with the timing assumption that an entrant starts producing only one period after entry, hence being able to 'learn' the average product price during the entry period. ${ }^{16}$

The total demand for the output of firm $\omega$ is thus

$$
y_{t}^{D}(\omega) \equiv\left(\frac{p_{t}(\omega)}{P_{t}}\right)^{-\theta}\left(C_{t}+P A C_{t}\right)
$$

where $P A C_{t} \equiv N_{t} \operatorname{pac}_{t}(\omega)$, and we used symmetry across firms in the definition of the aggregate demand of the consumption basket for price adjustment purposes $P A C_{t}$.

Let $\rho_{t}(\omega) \equiv p_{t}(\omega) / P_{t}$ denote the real price of firm $\omega$ 's output. Then, firm $\omega$ 's real profit in

\footnotetext{
${ }^{15}$ We relax this assumption below.

${ }^{16}$ Symmetry of the equilibrium will imply $p_{t-1}(\omega)=p_{t-1} \forall \omega$.
} 
period $t$ (distributed to households as dividend) can be written as

$$
d_{t}(\omega)=\rho_{t}(\omega) y_{t}^{D}(\omega)-w_{t} l_{t}(\omega)-\frac{\kappa}{2}\left(\frac{p_{t}(\omega)}{p_{t-1}(\omega)}-1\right)^{2} \rho_{t}(\omega) y_{t}^{D}(\omega)
$$

The real value of the firm at time $t$ (in units of consumption) is the expected present discounted value of future profits from $t+1$ on, discounted with the household's stochastic discount factor (see below):

$$
v_{t}(\omega)=E_{t} \sum_{s=t+1}^{\infty} \Lambda_{t, s} d_{s}(\omega)
$$

where $\Lambda_{t, s} \equiv[\beta(1-\delta)]^{s-t} U_{C}\left(C_{s}, L_{s}\right) / U_{C}\left(C_{t}, L_{t}\right)$ is the discount factor applied by households to future profits from firm $\omega$ (which faces a probability $\delta$ of being hit with the "death" shock in each period).

At time $t$, firm $\omega$ chooses $l_{t}(\omega)$ and $p_{t}(\omega)$ to maximize $d_{t}(\omega)+v_{t}(\omega)$ subject to $y_{t}(\omega)=y_{t}^{D}(\omega)$, taking $w_{t}, P_{t}, C_{t}, P A C_{t}$, and $Z_{t}$ as given. Letting $\lambda_{t}(\omega)$ denote the Lagrange multiplier on the constraint $y_{t}(\omega)=y_{t}^{D}(\omega)$, the first-order condition with respect to $l_{t}(\omega)$ yields:

$$
\lambda_{t}(\omega)=\frac{w_{t}}{Z_{t}}
$$

The shadow value of an extra unit of output is simply the firm's marginal cost, common across all firms in the economy.

The first-order condition with respect to $p_{t}(\omega)$ yields:

$$
p_{t}(\omega)=\mu_{t}(\omega) P_{t} \lambda_{t}(\omega)
$$

Firm $\omega$ sets the price as a markup $\left(\mu_{t}(\omega)\right)$ over nominal marginal cost, where the markup $\mu_{t}(\omega)$ is given by

$$
\begin{aligned}
\mu_{t}(\omega) & \equiv \frac{\theta y_{t}(\omega)}{(\theta-1) y_{t}(\omega)\left[1-\frac{\kappa}{2}\left(\frac{p_{t}(\omega)}{p_{t-1}(\omega)}-1\right)^{2}\right]+\kappa \Upsilon_{t}}, \\
\Upsilon_{t} & \equiv y_{t}(\omega) \frac{p_{t}(\omega)}{p_{t-1}(\omega)}\left(\frac{p_{t}(\omega)}{p_{t-1}(\omega)}-1\right)-E_{t}\left[\Lambda_{t, t+1} y_{t+1}(\omega) \frac{P_{t}}{P_{t+1}}\left(\frac{p_{t+1}(\omega)}{p_{t}(\omega)}\right)^{2}\left(\frac{p_{t+1}(\omega)}{p_{t}(\omega)}-1\right)\right] .
\end{aligned}
$$

As expected, the markup reduces to $\theta /(\theta-1)$ in the absence of nominal rigidity $(\kappa=0)$ or if the price $p_{t}(\omega)$ is constant. 


\section{Firm Entry and Exit}

In every period, there is an unbounded mass of prospective entrants. These entrants are forward looking, and correctly anticipate their future expected profits $d_{t}(\omega)$ in every period as well as the probability $\delta$ (in every period) of incurring the exit-inducing shock. We assume that entrants at time $t$ only start producing at time $t+1$, which introduces a one-period time-to-build lag in the model. The exogenous exit shock occurs at the very end of the time period (after production and entry). A proportion $\delta$ of new entrants will therefore never produce. Prospective entrants in period $t$ compute their expected post-entry value given by the present discounted value of their expected stream of profits $v_{t}(\omega)$. This also represents the average value of incumbent firms after production has occurred (since both new entrants and incumbents then face the same probability $1-\delta$ of survival and production in the subsequent period). Entry occurs until firm value is equalized with the entry cost, leading to the free entry condition $v_{t}(\omega)=w_{t} f_{E, t} / Z_{t}$. This condition holds so long as the mass $N_{E, t}$ of entrants is positive. We assume that macroeconomic shocks are small enough for this condition to hold in every period. ${ }^{17}$ Finally, the timing of entry and production we have assumed implies that the number of producing firms during period $t$ is given by $N_{t}=(1-\delta)\left(N_{t-1}+N_{E, t-1}\right)$.

\section{Symmetric Firm Equilibrium}

In equilibrium, all firms make identical choices. Hence, $\lambda_{t}(\omega)=\lambda_{t}, p_{t}(\omega)=p_{t}, \mu_{t}(\omega)=\mu_{t}$, $\rho_{t}(\omega)=\rho_{t}, l_{t}(\omega)=l_{t}, y_{t}(\omega)=y_{t}, p a c_{t}(\omega)=p a c_{t}, d_{t}(\omega)=d_{t}$, and $v_{t}(\omega)=v_{t}$. The aggregate output of the consumption basket (used for consumption and to pay price adjustment costs) is

$$
Y_{t}^{C} \equiv C_{t}+P A C_{t}=N_{t} \rho_{t} y_{t}=N_{t} \rho_{t} Z_{t} l_{t}
$$

The expression of the price index $P_{t}$ implies that the relative price $\rho_{t}$ and the number of producing firms $N_{t}$ are tied by the "variety effect" equation $\rho_{t}=p_{t} / P_{t}=\left(N_{t}\right)^{\frac{1}{\theta-1}}$.

Let $\pi_{t}$ denote inflation in producer prices: $\pi_{t} \equiv p_{t} / p_{t-1}-1$. Then, we can write:

$$
\mu_{t}=\frac{\theta}{(\theta-1)\left[1-\frac{\kappa}{2}\left(\pi_{t}\right)^{2}\right]+\kappa\left\{\left(1+\pi_{t}\right) \pi_{t}-\beta(1-\delta) E_{t}\left[\frac{C_{t}}{C_{t+1}} \frac{N_{t}}{N_{t+1}} \frac{Y_{t+1}^{C}}{Y_{t}^{C}}\left(1+\pi_{t+1}\right) \pi_{t+1}\right]\right\}}
$$

This can be simplified further by noting that $P A C_{t}=\kappa\left(\pi_{t}\right)^{2} Y_{t}^{C} / 2$, so that $C_{t}=\left[1-\kappa\left(\pi_{t}\right)^{2} / 2\right] Y_{t}^{C}$,

\footnotetext{
${ }^{17}$ If $v_{t}(\omega)<w_{t} f_{E, t} / Z_{t}$, prospective entrants will not be willing to incur the sunk entry cost, resulting in zero entry.
} 
to obtain:

$$
\mu_{t}=\frac{\theta}{(\theta-1)\left[1-\frac{\kappa}{2}\left(\pi_{t}\right)^{2}\right]+\kappa\left\{\left(1+\pi_{t}\right) \pi_{t}-\beta(1-\delta) E_{t}\left[\frac{1-\frac{\kappa}{2}\left(\pi_{t}\right)^{2}}{1-\frac{\kappa}{2}\left(\pi_{t+1}\right)^{2}} \frac{N_{t}}{N_{t+1}}\left(1+\pi_{t+1}\right) \pi_{t+1}\right]\right\}} .
$$

Log-linearization of this equation delivers our model's New Keynesian Phillips curve incorporating the effect of endogenous product variety, which we discuss in detail in Section 4.

\section{Household Budget Constraint, Saving, and Labor Supply}

Households hold two types of assets: shares in a mutual fund of firms and bonds. Let $x_{t}$ be the share in the mutual fund of firms held by the representative household entering period $t$. The mutual fund pays a total profit in each period (in units of currency) that is equal to the total profit of all firms that produce in that period, $P_{t} N_{t} d_{t}$. During period $t$, the representative household buys $x_{t+1}$ shares in a mutual fund of $N_{H, t} \equiv N_{t}+N_{E, t}$ firms (those already operating at time $t$ and the new entrants). Only $N_{t+1}=(1-\delta) N_{H, t}$ firms will produce and pay dividends at time $t+1$. Since the household does not know which firms will be hit by the exogenous exit shock $\delta$ at the very end of period $t$, it finances the continuing operation of all pre-existing firms and all new entrants during period $t$. The date $t$ price of a claim to the future profit stream of the mutual fund of $N_{H, t}$ firms is equal to the average nominal price of claims to future profits of home firms, $V_{t} \equiv P_{t} v_{t}$.

The household enters period $t$ with nominal bond holdings $B_{N, t}$ and mutual fund share holdings $x_{t}$. It receives gross interest income on bond holdings, dividend income on mutual fund share holdings and the value of selling its initial share position, and labor income. The household allocates these resources between purchases of bonds and shares to be carried into next period and consumption. The period budget constraint (in units of currency) is:

$$
B_{N, t+1}+V_{t} N_{H, t} x_{t+1}+P_{t} C_{t}=\left(1+i_{t-1}\right) B_{N, t}+\left(D_{t}+V_{t}\right) N_{t} x_{t}+\left(1+\tau_{t}^{L}\right) W_{t} L_{t}+T_{t}^{L},
$$

where $i_{t-1}$ denotes the nominal interest rate on holdings of bonds between $t-1$ and $t, D_{t}$ denotes nominal dividends $\left(D_{t} \equiv P_{t} d_{t}\right), \tau_{t}^{L}$ is a labor subsidy whose role we discuss below, and $T_{t}^{L}$ is a lump-sum tax satisfying the constraint $T_{t}^{L}=-\tau_{t}^{L} W_{t} L_{t}$ in equilibrium. Dividing both sides by $P_{t}$ and denoting holdings of bonds in units of consumption with $B_{t+1} \equiv B_{N, t+1} / P_{t}$, we can write

$$
B_{t+1}+v_{t} N_{H, t} x_{t+1}+C_{t}=\left(1+r_{t}\right) B_{t}+\left(d_{t}+v_{t}\right) N_{t} x_{t}+\left(1+\tau_{t}^{L}\right) w_{t} L_{t}+t_{t}^{L}
$$


where $1+r_{t}$ is the gross, consumption-based, real interest rate on holdings of bonds between $t-1$ and $t$, defined by $1+r_{t} \equiv\left(1+i_{t-1}\right) /\left(1+\pi_{t}^{C}\right)$, with $\pi_{t}^{C} \equiv P_{t} / P_{t-1}-1$, and $t_{t}^{L} \equiv T_{t}^{L} / P_{t}$. The home household maximizes its expected intertemporal utility subject to this budget constraint.

The Euler equations for bond and share holdings are:

$$
\left(C_{t}\right)^{-1}=\beta E_{t}\left[\frac{1+i_{t}}{1+\pi_{t+1}^{C}}\left(C_{t+1}\right)^{-1}\right] \quad \text { and } \quad v_{t}=\beta(1-\delta) E_{t}\left[\left(\frac{C_{t+1}}{C_{t}}\right)^{-1}\left(v_{t+1}+d_{t+1}\right)\right]
$$

As expected, forward iteration of the equation for share holdings and absence of speculative bubbles yield the asset price solution in equation (1). ${ }^{18}$

The first-order condition for the optimal choice of labor effort requires that the marginal disutility of labor be equal to the marginal utility from consuming the real wage received for an additional unit of labor:

$$
\chi\left(L_{t}\right)^{\frac{1}{\varphi}}=\left(1+\tau_{t}^{L}\right) \frac{w_{t}}{C_{t}} .
$$

\section{Aggregate Accounting and Equilibrium}

Aggregating the budget constraint (3) across households and imposing the equilibrium conditions $B_{t+1}=B_{t}=0$ and $x_{t+1}=x_{t}=1, \forall t$, yields the aggregate accounting identity $Y_{t} \equiv C_{t}+N_{E, t} v_{t}=$ $w_{t} L_{t}+N_{t} d_{t}$, where we defined GDP, $Y_{t}$ : Consumption plus investment (in new firms) must be equal to income (labor income plus dividend income).

Labor market equilibrium requires $N_{t} l_{t}+N_{E, t} f_{E, t} / Z_{t}=L_{t}$ : The total amount of labor used in production and to set up the new entrants' plants must equal aggregate labor supply. (Of course, this condition is redundant once equilibrium in goods and asset markets is imposed.) The equilibrium conditions of our benchmark model are summarized in Table 1.

\footnotetext{
${ }^{18}$ We omit the transversality conditions for bonds and shares that must be satisfied to ensure optimality.
} 
Our analysis of optimal monetary policy builds on results in Bilbiie, Ghironi, and Melitz (2006). We show there that the flexible-price version of the economy described above is efficient - the competitive equilibrium coincides with the social planner's optimum - if labor supply is inelastic $(\varphi=0)$ and $L_{t}=1 \forall t$. The reason is that, with C.E.S. Dixit-Stiglitz preferences, the profit destruction externality generated by producer entry (which reduces demand for each individual firm) is exactly matched by the consumer's love for variety - both determined by the elasticity of substitution $\theta$. The flexible-price economy is inefficient if $\varphi>0$ because there is a misalignment of markups across the items the consumer cares about (consumption, priced at a markup over marginal cost, and leisure, priced competitively), but efficiency is restored if the labor subsidy $\tau_{t}^{L}$ is equal to the net markup of pricing over marginal cost, $1 /(\theta-1)$ in all periods. This subsidy aligns markups across consumption goods and leisure while preserving the expected profitability of firm entry, thus inducing the efficient equilibrium. We assume that $\tau_{t}^{L}=1 /(\theta-1) \forall t$ below.

Sticky prices imply a time-varying markup whenever producer prices are changing over time. As shown in Bilbiie, Ghironi, and Melitz (2006), markup non-synchronization across periods (as well as across states and arguments of the utility function) generates inefficiency compared to the planner's optimum. Since in this particular model time variation of the markup in the competitive equilibrium is due to producer price inflation, we expect a zero rate of inflation in producer prices to be the optimal monetary policy chosen by a planner. The following proposition confirms that this is indeed the case. To isolate our main result, we prove the proposition for the case of inelastic labor and then briefly discuss the elastic labor case. As in Bilbiie, Ghironi, and Melitz (2006), we assume that the planner chooses the amount of labor that is allocated to producing existing varieties, which, in turn, determines the number of produced varieties. In addition, in this paper, the planner also chooses the rate of producer price inflation.

Proposition 1 The optimal rate of producer price inflation $\pi_{t}$ chosen by a social planner is zero.

The proof of Proposition 1 is in an Appendix available on request. The intuition is straightforward: Producer price inflation acts as a tax on firm profits in our model, as can be seen directly in the corresponding equation in Table 1 (inflation erodes the share of total profits in consumption output both directly and by its impact on markups). It distorts firm entry decisions and the allocation of labor to creation of new firms versus production of existing goods, resulting in suboptimal consumption and lower welfare. Optimal policy, therefore, aims to stabilize producer price inflation at zero. Importantly, however, while producer prices must be stabilized, the optimal rate 
of consumer price inflation must move freely to accommodate changes in the number of varieties:

$$
1+\pi_{t}^{C *}=\left(\frac{\rho_{t}^{*}}{\rho_{t-1}^{*}}\right)^{-1}=\left(\frac{N_{t}^{*}}{N_{t-1}^{*}}\right)^{-\frac{1}{\theta-1}}
$$

where a star denotes variables in the efficient equilibrium. Given the evidence of bias in the measurement of CPI inflation (precisely due to poor accounting for new varieties) convincingly documented by Broda and Weinstein (2006), we view this normative implication of our model as "good news." The central bank should target inflation in producer prices rather than (mismeasured) CPI inflation.

When labor supply is elastic, the subsidy $\tau_{t}^{L}=1 /(\theta-1)$ ensures that the flexible-price equilibrium is efficient, removing the wedge otherwise present between the marginal rates of substitution and transformation between consumption and leisure. In this case, price stickiness distorts both the total amount of labor supplied and its allocation to creation of new firms and production of existing goods. It is easy to verify that a zero rate of inflation in producer prices is still the optimal monetary policy.

The optimality of producer price stability with inelastic labor supply highlights a new argument for price stability (at the producer level) implied by endogenous entry and product variety. In a model with exogenously fixed number of firms and inelastic labor supply, time variation in the markup would have no impact on the equilibrium path of consumption and welfare: Consumption would be simply determined by the exogenous productivity and labor supply regardless of markup dynamics. Endogenous entry and product variety imply that markup variation reduces welfare by distorting entry decisions and the allocation of the fixed amount of labor to firm creation versus production of existing goods. This introduces a role for monetary policy in welfare maximization by stabilizing producer price inflation at zero - and the markup at its flexible-price level. We discuss implementation of the optimal monetary policy by setting the nominal interest rate below.

\section{The New Keynesian Phillips Curve and the Log-Linear Model}

This section describes the implications of endogenous entry and product variety for the New Keynesian Phillips curve and presents the key log-linear equations of the model. 


\section{The New Keynesian Phillips Curve}

To study the propagation of shocks and compute second moments of the endogenous variables implied by assumptions on the processes for exogenous shocks, we log-linearize the model around the efficient steady state with zero inflation under assumptions of log-normality and homoskedasticity. We denote percent deviations from steady state with sans serif fonts. Our model's version of the New Keynesian Phillips curve follows from log-linearizing equation (2):

$$
\pi_{t}=\beta(1-\delta) E_{t} \pi_{t+1}-\frac{\theta-1}{\kappa} \mu_{t}
$$

where $\pi_{t}$ and $\mu_{t}$ now denote percent deviations from steady state (of gross inflation in the case of $\left.\pi_{t}\right)$.

Since $\rho_{t}=p_{t} / P_{t}=\left(N_{t}\right)^{\frac{1}{\theta-1}}$ and optimal firm pricing implies $\mu_{t}=\rho_{t} / \lambda_{t}=\rho_{t} Z_{t} / w_{t}$, it follows that $\mu_{t}=\left(N_{t}\right)^{\frac{1}{\theta-1}} Z_{t} / w_{t}$, or, in log-linear terms:

$$
\mu_{t}=\frac{1}{\theta-1} \mathrm{~N}_{t}-\left(\mathrm{w}_{t}-\mathrm{Z}_{t}\right)
$$

(With a constant number of firms, this relation reduces to the familiar negative relation between markup and marginal cost of the benchmark New Keynesian model.) Substituting (5) into (4) yields:

$$
\pi_{t}=\beta(1-\delta) E_{t} \pi_{t+1}+\frac{\theta-1}{\kappa}\left(\mathrm{w}_{t}-\mathrm{Z}_{t}\right)-\frac{1}{\kappa} \mathrm{N}_{t} .
$$

Equation (6) is a New Keynesian Phillips curve relation that ties firm-level inflation dynamics to marginal cost in a standard fashion. Importantly, the effect of marginal cost is adjusted to reflect the number of producers that operate in the economy. This is a predetermined, state variable, which introduces directly a degree of endogenous persistence in the dynamics of product price inflation in the Phillips curve.

Furthermore, our model links the dynamics of inflation to asset prices in an endogenous way, as can be seen by combining (6) with the log-linear free entry condition to obtain:

$$
\pi_{t}=\beta(1-\delta) E_{t} \pi_{t+1}+\frac{\theta-1}{\kappa}\left(\mathrm{v}_{t}-\mathrm{f}_{E, t}\right)-\frac{1}{\kappa} \mathrm{N}_{t} .
$$

This equation ties inflation dynamics to the relative price of investment in new firms. It stipulates that, for given expected inflation and number of firms, inflation is positively related to equity prices. 
Together with the no-arbitrage condition between bonds and equity implied by optimal household behavior, this connection between inflation and equity prices (and thus capital accumulation in our model) plays a crucial role for the determinacy and stability properties of interest rate setting that we discuss below.

Finally, using the definition of CPI inflation, we can write the New Keynesian Phillips curve for consumption-based inflation:

$$
\pi_{t}^{C}=\beta(1-\delta) E_{t} \pi_{t+1}^{C}+\frac{\theta-1}{\kappa}\left(\mathrm{w}_{t}-\mathrm{Z}_{t}\right)-\frac{1}{\kappa} \mathrm{N}_{t}-\frac{1}{\theta-1}\left[\mathrm{~N}_{t}-\mathrm{N}_{t-1}-\beta(1-\delta)\left(\mathrm{N}_{t+1}-\mathrm{N}_{t}\right)\right]
$$

where $\pi_{t}^{C}$ now denotes the percent deviation of the gross CPI inflation rate from the steady state. Consumption-based inflation displays an additional degree of endogenous persistence relative to firm-level inflation in that it depends directly on the number of firms that produced at time $t-1$, which was determined in period $t-2$.

\section{Implications for Empirical Exercises}

Existing empirical studies estimating the New Keynesian Phillips curve (4), such as Sbordone (2002) and Galí and Gertler (1999), proxy the (unobservable) markup variable with the inverse of the labor share. This is an approximation that holds exactly in a model without endogenous variety. In our model with endogenous variety, however, this relationship no longer holds. Indeed, if one believes product variety to be important for business cycles, the proxy for the markup that one should use is the inverse of the share of labor (in consumption output) beyond the 'overhead' quantity (from an aggregate perspective) used to set up new product lines, $\mu_{t}=Y_{t}^{C} /\left[w_{t}\left(L_{t}-L_{E, t}\right)\right]$. This markup measure corresponds closely to the labor share measure used by Rotemberg and Woodford (1999) that takes into account overhead labor. Log-linearization of this equation, when replaced into (4), delivers a relation that is testable empirically. ${ }^{19}$ Alternatively, exploiting the equation for profits, one could use the inverse of (one minus) the profit share, $\mu_{t}=\left(1-D_{t}^{G} / Y_{t}^{C}\right)^{-1}$, as a proxy for markups, where $D_{t}^{G} \equiv d_{t} N_{t}+\frac{\kappa}{2}\left(\pi_{t}\right)^{2} Y_{t}^{C}$ are profits gross of the costs of price adjustment. Note that since these costs are zero when log-linearizing around a zero-inflation steady-state (and hence consumption is equal to consumption output and gross profits are equal to net profits), the

\footnotetext{
${ }^{19}$ Sbordone (2002) indeed showed that using this corrected measure does not affect the estimates obtained when using the baseline markup proxy. Our framework suggests a specific calibration scheme for the share of overhead labor used in this correction, namely: $L_{E} / L=\delta(\mu-1) /(r+\delta \mu)$, where we denote steady-state levels of variables by dropping the subscript $t$. Under our baseline parametrization below, this is approximately 0.20 ; the upper bound suggested by the empirical results of Basu and Kimball (1997) is 0.25.
} 
empirically usable equation will feature only observable variables, i.e., consumption and total profit receipts (or dividends). ${ }^{20}$

A further implication of our framework for empirical exercises comes from the natural distinction between consumer and producer price inflation in our model: Our framework implies that, in order to overcome measurement issues inherent in using CPI inflation, empirical studies of the Phillips curve should concentrate on producer price inflation (which is also the relevant objective for monetary policy). Construction of CPI data by statistical agencies does not adjust for availability of new varieties in the specific functional form dictated by the welfare-consistent price index. Furthermore, adjustment for variety, when it happens, certainly does not happen at the frequency represented by periods in our model. Actual CPI data are closer to $p_{t}$ (the average price level in our economy) than $P_{t}$. For this reason, when investigating the properties of the model in relation to the data (for instance, when computing second moments below or in the specification of policy rules that allow for reaction to measured real quantities), one should focus on real variables deflated by a data-consistent price index. For any variable $X_{t}$ in units of the consumption basket, such data-consistent counterpart is obtained as $X_{R, t} \equiv P_{t} X_{t} / p_{t}=X_{t} / \rho_{t}{ }^{21}$

Related to this measurement issue, our framework implies an 'endogeneity bias' in cost-push shocks in much empirical literature on the New Keynesian Phillips curve. An endogenous term that depends on $N_{t}$ (due the measurement bias from not accounting for variety) is attributed to exogenous cost-push shocks when estimating the Phillips curve equation (6) using a proxy for marginal cost without variety.

When the variety effect is removed from the welfare-consistent equity price, the Phillips curve (7) becomes:

$$
\pi_{t}=\beta(1-\delta) E_{t} \pi_{t+1}+\frac{\theta-1}{\kappa}\left(\mathrm{v}_{R, t}-\mathrm{f}_{E, t}\right)
$$

where $v_{R, t}$ is the value of the firm/price of shares net of the variety effect. For given expectations of future inflation, actual inflation is increasing in the data-consistent price of equity.

\footnotetext{
${ }^{20}$ We leave estimation of Phillips curves using these alternative profit-based proxies for the markup for future research.

${ }^{21}$ Returning to the normative prescription that the central bank should stabilize producer prices, our model implies that if the central bank targeted CPI inflation, the bias in its measurement would indeed be beneficial to the extent that biased CPI inflation is closer to producer price inflation than welfare-consistent consumer price inflation.
} 


\section{The Log-Linear Model}

The log-linear model can be reduced to the following equations (plus the New Keynesian Phillips curve (4)):

$$
\begin{aligned}
\mathrm{N}_{t+1} & =[1+r+\psi] \mathrm{N}_{t}-(r+\delta+\psi)(\theta-1) \mathrm{C}_{t}-\psi(\theta-1) \mu_{t}+((r+\delta+\psi)(\theta-1)+\delta) \mathrm{Z}_{t}-\delta \mathrm{f}_{E, t} \\
\mathrm{C}_{t} & =\frac{1-\delta}{1+r} E_{t} \mathrm{C}_{t+1}-\left[\frac{1-\delta}{1+r} \frac{1}{\theta-1}-\frac{r+\delta}{1+r}\right] \mathrm{N}_{t+1}+\frac{1}{\theta-1} \mathrm{~N}_{t} \\
+ & {\left[\frac{1-\delta}{1+r}-\frac{r+\delta}{1+r}(\theta-1)\right] \mu_{t+1}-\mu_{t}-\frac{1-\delta}{1+r} E_{t} \mathrm{f}_{E, t+1}+\mathrm{f}_{E, t} } \\
E_{t} \mathrm{C}_{t+1} & =\mathrm{C}_{t}+\mathrm{i}_{t}-E_{t} \pi_{t+1}+\frac{1}{\theta-1} \mathrm{~N}_{t+1}-\frac{1}{\theta-1} \mathrm{~N}_{t}
\end{aligned}
$$

where we defined $\psi \equiv \varphi[(r+\delta)(\theta-1)+\delta] /(\theta-1)$, which is zero when labor supply is inelastic. The model is closed by specifying the conduct of monetary policy (via the setting of the nominal interest rate $\mathrm{i}_{t}$ ) over the business cycle, which we discuss below.

\section{Monetary Policy over the Business Cycle}

In this section, we discuss determinacy and stability properties of simple rules for nominal interest rate setting over the business cycle and the implementation of the optimal policy of producer price stability.

\section{Simple Policy Rules}

For illustrative purposes, we consider the following class of simple inflation-targeting rules for interest rate setting:

$$
\mathbf{i}_{t}=\tau_{i} \mathbf{i}_{t-1}+\tau E_{t} \pi_{t+s}+\tau_{C} E_{t} \pi_{t+s}^{C}+\xi_{t}^{i}, \quad 1>\tau_{i} \geq 0, \tau \geq 0, \tau_{C} \geq 0, s=0,1 .
$$

where $\xi_{t}^{i}$ is an exogenous shock capturing the non-systematic component of monetary policy. We assume that $\tau_{C}=0$ when $\tau>0$ and vice versa, restricting the central bank to reacting to either producer or consumer price inflation. ${ }^{22}$ For the reasons we discussed above, a response to welfarebased CPI inflation is suboptimal (and not feasible in reality due to the measurement problems

\footnotetext{
${ }^{22}$ We consider rules featuring a response to GDP $Y_{R, t}$ in Section 7.
} 
we mentioned). In considering this scenario, we abstract from normative prescriptions and measurement issues; rather, we ask the question: What would the response of the economy to various shocks be if the central bank could monitor movements in welfare-consistent CPI inflation and followed a rule involving the latter?

\section{Determinacy and Stability}

In this section, we study the determinacy and stability properties of our model under different monetary policy rules. To analyze local determinacy and stability of the rational expectation equilibrium, we can focus on the perfect foresight, no-fundamental-shock version of the system formed by (4), (10), (11), and the equation obtained by substituting the monetary policy rule (13) into the Euler equation for bonds (12). To begin with, consider the simple rule in which the central bank is responding to expected producer price inflation with no smoothing: $\mathrm{i}_{t}=\tau E_{t} \pi_{t+1}$. The following Proposition establishes that the Taylor Principle holds in our model economy for all plausible combinations of parameter values.

Proposition 2 Let $\gamma \equiv[1-\beta(1-\delta)] /[\beta(1-\delta)]$. Assume that $\varphi=0$, and $\beta$, $\delta$, and $\theta$ are such that $1-\gamma(\theta-1)>0, \beta>1 / 2, \theta>2$, and $\tau<\bar{\tau}=(\kappa+\theta-1) /(\theta-1)$. Then $\tau>1$ is necessary and sufficient for local determinacy and stability.

As for Proposition 1, the proof of Proposition 2 is in the Appendix available on request. We remark that the parameter restrictions in Proposition 2 are sufficient conditions for the Taylor Principle to hold, and they are extremely weak. For instance, the values of $\kappa$ and $\theta$ that we consider below $(\kappa=77$ and $\theta=3.8)$ imply $\bar{\tau}=28.5$ : The sufficient condition $\tau<28.5$ is satisfied by any realistic parametrization of interest rate setting. Moreover, while we cannot prove it analytically, we verify numerically that determinacy and stability hold for values of $\tau$ well above the threshold $\bar{\tau}$ for the parameter values we consider.

Validity of the Taylor Principle is an important result given the debate on the Taylor Principle in models with physical capital accumulation. Dupor (2001) shows that passive interest rate setting $(\tau<1)$ is necessary and sufficient for local determinacy and stability in a continuous-time model with physical capital. Carlstrom and Fuerst (2005) study the issue in a discrete-time model with capital and conclude that it is essentially impossible to achieve determinacy with forward-looking interest rate setting. Our result shows that the standard Taylor Principle is restored when capital accumulation takes the form of the endogenous creation of new production lines. 
Since the validity of the Taylor principle in our setup is in striking contrast to results of models with traditional physical capital, an intuitive explanation of this difference is in order. Indeed, the mechanism for this result in our model is centered precisely on the role of the endogenous price of equity - the value of the firm - in our New Keynesian model with free entry. As we anticipated, the explanation relies on one hand on the Phillips curve (9) above that relates inflation and asset prices (net of the variety effect) $v_{R, t}$ and on the other hand on the no-arbitrage condition implied by the Euler equations for bonds and shares. This condition can be written as:

$$
\mathrm{i}_{t}-\mathrm{E}_{t} \pi_{t+1}=-\mathrm{v}_{R, t}+\frac{1-\delta}{1+r} \mathrm{E}_{t} \mathrm{v}_{R, t+1}+\frac{r+\delta}{1+r} \mathrm{E}_{t} \mathrm{~d}_{R, t+1} .
$$

Focus first on the policy rule studied in Proposition 2, where the relevant inflation objective is expected product price inflation, and consider the following experiment. Suppose that a sunspot shock unrelated to any fundamental hits the economy, and that (without losing generality) it is located in inflationary expectations, so that all other expected values are taken as given. We wish to show that if the policy rule is passive (the Taylor Principle is violated), this sunspot shock will have real effects, whereas if the policy rule is active the sunspot has no effect. When the Taylor Principle is violated, an increase in expected inflation triggers a fall in the real interest rate. From the no-arbitrage condition (14), this implies that the data-consistent price of shares must rise (a fall in the real return on bonds must be matched by a fall in the real return on shares, which, for fixed expected dividend and future price, means an increase in the share price today). But an increase in the share price implies, by (9), that actual inflation today will rise, and hence that the sunspot is self-fulfilling. When the Taylor Principle is satisfied, the opposite holds: The sunspot triggers an increase in the real interest rate, a fall in today's share price by no-arbitrage, and a fall in today's inflation by the Phillips curve, making the sunspot vanish. ${ }^{23}$

The same mechanism can be easily verified to hold for a policy rule responding to contemporaneous producer price inflation, and indeed to (contemporaneous or expected) inflation in consumer prices. Therefore, we omit the formal statements and proofs of the Taylor Principle for those cases to save space. ${ }^{24}$

\footnotetext{
${ }^{23}$ This argument does not hinge on having removed the variety effect from equity prices and dividends. The same argument can be made by using the Phillips curve equation (7) and the no-arbitrage condition in welfare-consistent terms.

${ }^{24}$ Details are available on request.
} 
A comparison of our results and intuition with those of Carlstrom and Fuerst (2005) allows us to further emphasize the crucial role of the different type of capital at the core of our model. Carlstrom and Fuerst show that indeterminacy occurs in a discrete-time model with physical capital when the central bank responds to expected future inflation because the no-arbitrage condition between bonds and capital contains no variable dated at time $t$. This happens because the expected return to capital depends only on future variables determining the marginal product of capital at time $t+1$. In turn, this implies that there is a zero root in the system, and indeterminacy. ${ }^{25}$ Instead, in our model, the expected return on shares depends on the price of shares today (an endogenous variable), hence removing this 'zero-root' problem. Indeed, through today's price of equity, our model provides a novel link between the no-arbitrage condition and the Phillips curve that is absent in models that do not feature endogenous variety and free entry.

\section{Implementing Price Stability with Endogenous Entry and Product Variety}

The efficient, flexible-price equilibrium requires the nominal interest rate to be equal to the 'Wicksellian' interest rate (in Woodford's, 2003, terminology), i.e., the interest rate $i_{t}^{*}$ that prevails when prices are flexible and producer price inflation is zero. In log-linear terms, the Wicksellian interest rate is:

$$
\mathrm{i}_{t}^{*}=E_{t} \mathrm{C}_{t+1}^{*}-\mathrm{C}_{t}^{*}-\frac{1}{\theta-1}\left(\mathrm{~N}_{t+1}^{*}-\mathrm{N}_{t}^{*}\right)=E_{t} \mathrm{C}_{t+1}^{*}-\mathrm{C}_{t}^{*}+\pi_{t+1}^{C *},
$$

where $E_{t} \mathrm{C}_{t+1}^{*}-\mathrm{C}_{t}^{*}$ is the risk-free, real interest rate of BGM and $\pi_{t+1}^{C *}$ is the optimal consumer price inflation that accommodates changes in variety between $t$ and $t+1$ (known at time $t$ ). Note, however, that commitment to the policy rule $\mathrm{i}_{t}=\mathrm{i}_{t}^{*}$ would result in equilibrium indeterminacy, as in the standard model with a fixed number of producers discussed in Woodford (2003), because nominal interest rate setting would contain no feedback to variables that are endogenous in the sticky-price equilibrium.

A simple interest rate rule that implements the efficient, flexible-price equilibrium is

$$
\hat{\imath}_{t}=\tau \pi_{t}+E_{t} \hat{Y}_{R, t+1}^{C}-\hat{Y}_{R, t}^{C}, \quad \tau>1
$$

where $\hat{\imath}_{t} \equiv i_{t}-i_{t}^{*}$ is the interest rate gap relative to the Wicksellian interest rate, and $\hat{Y}_{R, t}^{C}=\hat{C}_{R, t} \equiv$ $\mathrm{C}_{t}-[1 /(\theta-1)] \mathrm{N}_{t}-\left\{\mathrm{C}_{t}^{*}-[1 /(\theta-1)] \mathrm{N}_{t}^{*}\right\}=\mathrm{C}_{R, t}-\mathrm{C}_{R, t}^{*}$ is the gap between measured consumption

\footnotetext{
${ }^{25}$ The problem is only partially solved by the introduction of capital adjustment costs (introduced in order to endogenize the price of capital). Carlstrom and Fuerst show that the Taylor Principle is restored for forward-looking rules only for empirically implausible parametrizations of the adjustment cost.
} 
output and its flexible-price level. The interest rate rule (15) requires the monetary authority to track changes in the Wicksellian interest rate and in expected growth of the consumption output gap, and to respond more than proportionally to inflation. It is possible to verify that the following equation holds for the dynamics of the consumption output gap:

$$
E_{t} \hat{Y}_{R, t+1}^{C}-\hat{Y}_{R, t}^{C}=\hat{\imath}_{t}-E_{t} \pi_{t+1}
$$

Substituting the interest rate rule (15) into this equation yields $\tau \pi_{t}=E_{t} \pi_{t+1}$, which has unique solution $\pi_{t}=0 \forall t$ since the Taylor Principle is satisfied. In turn, zero producer price inflation in all periods implies $\hat{\mathrm{Y}}_{R, t}^{C}=0$, and, therefore, $\mathrm{i}_{t}=\mathrm{i}_{t}^{*} \forall t{ }^{26}$

\section{Business Cycles: Propagation and Second Moments}

In this section, we explore the properties of our benchmark model by means of numerical examples. We compute impulse responses to productivity, deregulation, and monetary policy shocks. Next, we compute second moments of our artificial economy and compare them to second moments in the data and those produced by the baseline BGM model with flexible prices and C.E.S. preferences. As shown in BGM, these moments (which also correspond to those under the optimal monetary policy in the sticky-price economy) are very close to those generated by the standard RBC model.

\section{Calibration}

In our baseline calibration, we interpret periods as quarters and set $\beta=0.99$ - a standard choice for quarterly business cycle models. We set the size of the exogenous firm exit shock $\delta=0.025$ to match the U.S. empirical level of 10 percent job destruction per year. ${ }^{27}$ We use the value of $\theta$ from Bernard, Eaton, Jensen, and Kortum (2003) and set $\theta=3.8$, which was calibrated to fit U.S. plant and macro trade data. ${ }^{28}$ We set initial productivity to $Z=1$. The initial steady-state entry cost

\footnotetext{
${ }^{26}$ Rule (15) is by no means the only interest rate rule that implements the optimal monetary policy. It is of course possible to design alternative rules that achieve this goal.

${ }^{27}$ Empirically, job destruction is induced by both firm exit and contraction. In our model, the "death" shock $\delta$ takes place at the product level. In a multi-product firm, the disappearance of a product generates job destruction without firm exit. Since we abstract from the explicit modeling of multi-product firms, we include this portion of job destruction in $\delta$. As a higher $\delta$ implies less persistent dynamics, our choice of $\delta$ is also consistent with not overstating the ability of the model to generate persistence.

${ }^{28}$ It may be argued that the value of $\theta$ results in a steady-state markup that is too high relative to the evidence. However, it is important to observe that, in models without any fixed cost, $\theta /(\theta-1)$ is a measure of both markup over marginal cost and average cost. In our model with entry costs, free entry ensures that firms earn zero profits net of the entry cost. This means that firms price at average cost (inclusive of the entry cost). Thus, although $\theta=3.8$ implies a fairly high markup over marginal cost, our parametrization delivers reasonable results with respect
} 
$f_{E}$ does not affect any impulse response; we therefore set $f_{E}=1$ without loss of generality. We consider different values for the elasticity of labor supply, $\varphi$, and we set the weight of the disutility of labor in the period utility function, $\chi$, so that the steady-state level of labor effort is 1 - and steady-state levels of all variables are the same - regardless of $\varphi .^{29}$ We set the price stickiness parameter $\kappa=77$, the value estimated by Ireland (2001). Although Ireland obtained this estimate using a different model, without entry and endogenous variety, our results are not sensitive to changes in the value of this parameter within a plausible range.

\section{Impulse Responses}

\section{Productivity}

Figure 1 shows the responses (percent deviations from steady state) to a 1 percent increase in productivity for the inelastic labor case. For consistence with the second moment results below, we assume productivity persistence 0.979 as in King and Rebelo (1999). The figure compares the efficient flexible-price equilibrium obtained under optimal monetary policy (blue, round markers) with three alternative parametrizations of the monetary policy rule (13). The first is a simple rule responding to expected producer price inflation, $\mathrm{i}_{t}=1.5 E_{t} \pi_{t+1}$ (red, cross markers); the second is a rule involving interest rate smoothing, $\mathrm{i}_{t}=0.8 \mathrm{i}_{t-1}+0.3 E_{t} \pi_{t+1}$ (green, square markers), which features the same long-run response to expected inflation (1.5) as the previous rule; and the third is a rule responding to expected welfare-consistent CPI inflation, $\mathrm{i}_{t}=1.5 E_{t} \pi_{t+1}^{C}$ (pink, star markers). Note that the difference between the responses under each of the simple rules and the optimal policy measures the gap relative to the flexible-price equilibrium under the alternative rules. The number of years after the shock is on the horizontal axis, and responses are normalized so that 0.3 (for instance) denotes 0.3 percent.

Focus on the responses under the optimal policy. The increase in productivity makes the business environment temporarily more attractive, drawing a higher number of entrants $\left(N_{E, t}\right)$, which translates into a gradual increase in the number of producers $\left(N_{t}\right)$ before entry and the stock of production lines return to the steady state. The larger number of producers induces marginal $\operatorname{cost}\left(w_{t} / Z_{t}-\right.$ not shown $)$ and the relative price of each product $\rho_{t}$ to increase gradually with unchanged markup. GDP $\left(Y_{t}\right)$ and consumption $\left(C_{t}\right)$ increase, and so does investment in new firms

to pricing and average costs. The main qualitative features of the impulse responses below are not affected if we set $\theta=6$, resulting in a 20 percent markup of price over marginal cost as in Rotemberg and Woodford (1992) and several other studies.

${ }^{29}$ This requires $\chi=0.924271$. 
$\left(v_{t}^{E} \equiv v_{t} N_{E, t}\right)$ as the fixed labor supply is reallocated toward creation of new products. Interestingly, firm-level output $\left(y_{t}\right)$ is below the steady state during most of the transition, except for an initial expansion. The effect of a higher relative price prevails on the expansion in consumption demand to push individual firm output below the steady state for much of the transition, with expansion in the number of producers and investment in new firms responsible for GDP remaining above the steady state throughout the transition. Notably, the dynamics of firm entry result in responses that persist beyond the duration of the exogenous shock, and, for some key variables, display a hump-shaped pattern. ${ }^{30}$

When comparing responses across policy rules, a remarkable feature of the results is that the dynamics of macroeconomic aggregates under the first two simple policy rules are strikingly similar to those in the flexible-price equilibrium. Indeed, the responses of GDP are virtually indistinguishable, and those of consumption and the number of producers are also very close. Equivalently, the changes in producer price inflation and the markup induced by technology shocks under these policy rules are small. It is worth stressing that this is in contrast with responses in the fixed-variety, benchmark New Keynesian model, where there are quantitatively significant deviations from the flexible-price equilibrium under such simple policy rules. In our model, instead, a simple rule such as $\mathrm{i}_{t}=1.5 E_{t} \pi_{t+1}$, despite not featuring an overly aggressive response to inflation, manages to bring the economy quite close to its first-best optimum. This is no longer true when monetary policy responds to welfare-consistent CPI inflation: There are more evident differences in the responses of consumption and the number of producers, stemming from the suboptimal response of the central bank to movements in welfare-based CPI inflation that reflect fluctuations in the number of products. ${ }^{31}$

Importantly, our model with entry can induce inflation and countercyclical markups, and potentially procyclical labor, in response to technology shocks. To understand this result, recall the intuition in the standard New Keynesian model, which implies deflation and procyclical markups in response to productivity increases: Marginal cost falls, prices decrease (there is deflation), but not by as much because of stickiness, so output increases and markups increase too - i.e., the markup is procyclical. In our model with entry, there is an additional channel of shock transmission working in the opposite direction: Positive productivity shocks increase future profits and the value of the

\footnotetext{
${ }^{30}$ The responses of several macroeconomic variables deflated by average prices (the producer price level $p_{t}$ ) rather than with the consumption-based price index are qualitatively similar. For instance, $C_{R, t}$ increases, with a humpshaped response except when policy responds to welfare-based CPI inflation. $Y_{R, t}$ also rises, although without a hump.

${ }^{31}$ Results from policy rules featuring a response to GDP are available on request.
} 
firm (it is more productive to create new goods). Entry puts pressure on labor demand, inducing marginal cost to increase in order to satisfy free entry. By this channel, prices increase, but not by as much, and output increases (both consumption and investment increase). There is inflation and the markup is countercyclical. Otherwise put, through the usual channel, labor demand by existing firms falls, the real wage falls, and the markup increases. Through the new channel, labor demand by entrants increases and, if it increases enough, it can overturn the usual effect and generate an increase in total labor demand, a higher real wage, and a countercyclical markup. Which channel dominates depends on parameter values (for instance, shock persistence). As shown in Figure 1, the new channel dominates on impact with the persistence that we use to compute second moments below.

\section{Deregulation}

Figure 2 shows the responses to a 1 percent, permanent deregulation shock (a lowering of the entry $\left.\operatorname{cost} f_{E, t}\right)$ with inelastic labor supply under the same policy scenarios as above.

Focus again on responses under the optimal policy. Deregulation attracts new entrants and firm value decreases (the relative price of the investment good falls). Since investment is relatively more attractive than consumption, there is intersectoral labor reallocation from the latter to the former. Consumption falls initially as households now postpone consumption to invest more in firms whose productivity has not increased. The number of firms starts increasing, but GDP initially falls as the decline in consumption dominates the increase in investment. All variables then move monotonically toward their new steady-state levels. A consequence of C.E.S. preferences is that the long run expansion of consumption is entirely driven by the extensive margin (the long-run increase in the number of producers), with output per firm back at the initial steady-state level.

As in the case of a productivity shock, the responses for the first two alternative policy rules, where the targeted measure of inflation is producer price inflation, are again very similar to the flexible-price responses. As for productivity, the difference is larger when the monetary authority responds to welfare-based CPI inflation, for the same reasons discussed above. The most notable difference with respect to the flexible-price case in all responses (but more so when the rule responds to welfare-based CPI inflation) concerns the dynamics of the consumer price index. Under the optimal policy, deregulation induces deflation in the welfare-based CPI (at a decreasing rate in absolute terms) precisely because there is an increase in the number of products (at a decreasing rate). Under the alternative rules, this response changes sign, positive inflation in the welfare-based 
CPI occurs, because the increase in producer price inflation is high enough to compensate the effect of the increase in the number of available varieties. This effect is strongest when the central bank responds to welfare-based CPI inflation.

\section{Monetary Policy}

The next set of responses, plotted in Figure 3, shows the effects of a purely transitory shock to the nominal interest rate - a 1 percent decrease with zero exogenous persistence. Because of the assumption of zero exogenous persistence, all responses are plotted for the policy rule involving interest rate smoothing (otherwise, the effect of the shock is very short-lived), but for different values of the labor supply elasticity, $\varphi=0,2$, and 4 , respectively. ${ }^{32}$ An interest rate cut generates inflation and a positive response of GDP (as measured both by $Y_{t}$ and the data-consistent counterpart, $Y_{R, t}$ ). Wages rise, consistent with conventional wisdom and the bulk of empirical evidence for the post1980 U.S. (for instance, Christiano, Eichenbaum, and Evans, 1999). However, the expansionary effect on GDP is combined with a contractionary impact effect on entry (and a gradual decrease in the number of producers) that conflicts with the evidence in Bergin and Corsetti (2005) and Lewis (2006). ${ }^{33}$ The fall in the number of entrants occurs because no-arbitrage requires the expected return on equity to fall along with the ex ante real return on bonds. The decrease in the expected return on equity is brought about by an increase in the price of shares today relative to the future: The procyclical impact response of the real wage translates into an increase in today's equity price via the free entry condition. The cost of firm creation - which requires labor - increases, and its expected return falls, inducing investment in new products to fall (the combination of prices that the household faces makes it relatively more attractive to consume rather than invest). This effect changes sign after a few years, when the real wage falls and share prices are below the steady state, making it attractive to invest in product creation. The contractionary effect of monetary expansions on entry relies crucially on the link between firm value and marginal cost implied by free entry. In Section 7 , we study a version of the model that breaks this link and implies an expansionary effect of monetary policy expansions on firm entry. ${ }^{34}$

\footnotetext{
${ }^{32}$ The inelastic labor case is in blue (round markers); $\varphi=2$ is in red (cross markers); and $\varphi=4$ is in green (square markers).

${ }^{33}$ Note, however, that Bergin and Corsetti find that unconditional correlations between a measure of expansionary monetary policy and measures of entry (gross or net) are negative.

${ }^{34}$ We should note, however, that if the economy started from a situation of zero entry (in which the free entry condition holds with inequality, $v<w f_{E} / Z$, and $N_{E}=0$ ), a strong enough monetary expansion could induce an increase in share prices that brings the economy to the 'entry' region studied in this paper (in which the entry condition holds with equality and there is a positive mass of entrants at all times). In that case, expansionary
} 


\section{Second Moments}

To further evaluate the properties of the sticky-price model, we compute the implied unconditional second moments of our artificial economy for some key macroeconomic variables and compare them to those of the data and those produced by the BGM flexible-price model with C.E.S. preferences. In this exercise, we focus on random shocks to $Z_{t}$ as the source of business cycle fluctuations, assuming that sunk entry costs are constant at $f_{E, t}=1$ and abstracting from exogenous monetary policy shocks. ${ }^{35}$ To start with, we compute moments of GDP, consumption, investment, and hours worked. We use the same productivity process as King and Rebelo (1999), with persistence 0.979 and a standard deviation of innovations equal to 0.0072, to facilitate comparison of results with the baseline RBC setup and BGM. As in King and Rebelo's benchmark calibration, we set $\varphi=2 .^{36}$ Under sticky prices, we assume that monetary policy follows the rule $\mathrm{i}_{t}=0.8 \mathrm{i}_{t-1}+0.3 E_{t} \pi_{t+1}$. This rule is empirically plausible based on the findings of a large empirical literature, which documents the importance of interest rate smoothing in Federal Reserve policy, its focus on inflation targeting since the 1980s, and the marginal significance of GDP responses. Table 2 presents the results. For each moment, the first number (bold fonts) is the empirical moment implied by the U.S. data reported in King and Rebelo (1999), the second number (normal fonts) is the moment generated by the flexible-price model (or optimal monetary policy under sticky prices), and the third number (italics) is the moment generated by the sticky-price model under the rule above. We compute model-implied second moments for HP-filtered variables for consistency with data and standard $\mathrm{RBC}$ practice, and we measure investment in our model with the real value of household investment in new firms $\left(v_{R, t} N_{E, t}\right)$.

monetary policy would have an expansionary effect on entry also in this version of the model.

${ }^{35}$ The empirical literature has downplayed the role of exogenous monetary policy as a source of fluctuations, focusing instead on the role of systematic policy in response to economic conditions as a mechanism for propagation of the cycle. See, for instance, Leeper, Sims, and Zha (1996).

${ }^{36}$ The period utility function is defined over leisure $\left(1-L_{t}\right)$ in King and Rebelo (1999), where the endowment of time in each period is normalized to 1 . The elasticity of labor supply is then the risk aversion to variations in leisure (set to 1 in their benchmark calibration) multiplied by $(1-L) / L$, where $L$ is steady-state effort, calibrated to $1 / 3$. This yields $\varphi=2$ in our specification. 
Table 2. Moments for: Data, BGM C.E.S. Model, and Sticky Prices

\begin{tabular}{l|ccc|cc|ccc|ccc|ccc}
\hline \hline Variable $X_{t}$ & \multicolumn{4}{|c|}{$\sigma_{X_{t}}$} & \multicolumn{3}{|c|}{$\sigma_{X_{t}} / \sigma_{Y_{R, t}}$} & \multicolumn{3}{c|}{$E\left[X_{t} X_{t-1}\right]$} & \multicolumn{3}{c}{$\operatorname{corr}\left(X_{t}, Y_{R, t}\right)$} \\
\hline$Y_{R, t}$ & $\mathbf{1 . 8 1}$ & 1.34 & 1.36 & $\mathbf{1 . 0 0}$ & & $\mathbf{0 . 8 4}$ & 0.70 & 0.70 & $\mathbf{1 . 0 0}$ & \\
\hline$C_{R, t}$ & $\mathbf{1 . 3 5}$ & 0.65 & 0.66 & $\mathbf{0 . 7 4}$ & 0.48 & 0.48 & $\mathbf{0 . 8 0}$ & 0.75 & 0.74 & $\mathbf{0 . 8 8}$ & 0.97 & 0.98 \\
\hline Investment, $v_{R, t} N_{E, t}$ & $\mathbf{5 . 3 0}$ & 5.23 & 5.20 & $\mathbf{2 . 9 3}$ & 3.90 & 3.82 & $\mathbf{0 . 8 7}$ & 0.69 & 0.69 & $\mathbf{0 . 8 0}$ & 0.99 & 0.99 \\
\hline$L_{t}$ & $\mathbf{1 . 7 9}$ & 0.63 & 0.63 & $\mathbf{0 . 9 9}$ & 0.47 & 0.46 & $\mathbf{0 . 8 8}$ & 0.69 & 0.69 & $\mathbf{0 . 8 8}$ & 0.98 & 0.98 \\
\hline
\end{tabular}

Source for data moments: King and Rebelo (1999)

The performance of the sticky-price model is virtually indistinguishable from that of the flexibleprice economy, which - in turn - is remarkably close to that of a benchmark RBC model in reproducing some key features of U.S. business cycles as documented in BGM. The similarity in performance across sticky- and flexible-price models is not surprising in the light of the similarity of impulse responses between the rule we are considering and the optimal policy that we discussed above. An empirically plausible degree of nominal rigidity does not significantly alter the performance of the model relative to the flexible-price counterpart once one takes into account that Federal Reserve policy appears not to have been too distant from optimal in the recent past. Under a plausible specification of monetary policy, the baseline sticky-price framework (as the flexibleprice one) faces the same well-known difficulties of the standard RBC model: Consumption and hours are too smooth relative to output; there is not enough endogenous persistence (as indicated by the first-order autocorrelations); and all real variables are too procyclical relative to the data. As far as inflation is concerned, the model produces a standard deviation of product price inflation equal to 0.01, autocorrelation 0.82 , and correlation with GDP -0.87 . The effect of slow movement in the number of producers contributes to the persistence of inflation as explained above.

Figure 4 shows the model-generated correlation of the markup with GDP at various lags and leads, comparing it to that documented by Rotemberg and Woodford (1999) and that generated by the BGM model with translog preferences. ${ }^{37}$ The flexible-price model with translog preferences almost perfectly reproduces the contemporaneous countercyclicality of the markup; furthermore,

\footnotetext{
${ }^{37}$ Of the various labor share-based empirical measures of the markup considered by Rotemberg and Woodford, the one that is most closely related to the markup in our model is the version with overhead labor, whose cyclicality is reported in column 2 of their Table 2, page 1066, and reproduced in Figure 4. As we mentioned above, this is because markups in our model can be written as the inverse of the share of labor (in consumption output) beyond the 'overhead' quantity used to set up new product lines, $\mu_{t}=Y_{t}^{C} /\left[w_{t}\left(L_{t}-L_{E, t}\right)\right]$. There is of course an additional issue: This measure is specified as a share of consumption output, not GDP as in Rotemberg and Woodford. For issues pertaining to cyclicality, however, this makes little difference, since the share of consumption in GDP is relatively acyclical.
} 
the time profile of its correlation with the business cycle is very similar to that documented by Rotemberg and Woodford. The markup is countercyclical with translog preferences because the elasticity of substitution across goods is tied to the number of producers, which increases during expansions. The time profile of the correlation is due to the slow response of the stock of producers to shocks, with GDP increasing on impact, and the number of producers responding gradually and with a lag. The sticky-price model with C.E.S. preferences generates excessive contemporaneous countercyclicality and fails to replicate the time profile of the correlation because the markup now determined by the dynamics of producer price inflation - is no longer tied to the number of producers. On the bright side, the sticky-price model with endogenous entry and product variety generates procyclical producer entry, qualitatively in line with empirical evidence, and procyclical aggregate profits: The contemporaneous correlation between $D_{R, t} \equiv N_{t} d_{R, t}$ and $Y_{R, t}$ is 0.95 . Even if the markup falls during expansions, aggregate profits increase due to the expansion in the number of producers. ${ }^{38}$

In sum, given plausible nominal rigidity and policy behavior for inflation-sensitive policymakers, the performance of the sticky-price model at replicating key business cycle moments is - not surprisingly - close to the flexible-price counterpart. The sticky price model fails to match the cyclicality of the markup, though endogenous variety generates procyclical profits. Interestingly, and consistent with the presence of an endogenous state variable in the New Keynesian Phillips curve (6), the model delivers a persistent inflation rate. This goes in the direction of ameliorating the inability of the standard setup to generate sufficient persistence highlighted by Fuhrer and Moore (1995).

\section{Extensions}

In this section, we discuss the implications of three extensions of the benchmark model above. First, we study a version of our model in which the tight link between firm value and marginal production cost implied by free entry is broken by assuming that entry requires purchasing units of the consumption basket rather than hiring labor. We show that this version of the model generates increased producer entry in response to expansionary monetary policy shocks. Second, returning to the benchmark specification of the entry cost, we remove the assumption that new entrants inherit the same degree of price stickiness as incumbents and we allow new entrants to take their first price

\footnotetext{
${ }^{38}$ Firm-level real profits $d_{R, t}$ increase on impact following a favorable productivity shock with persistence 0.979 , but quickly drop below the steady state and return to it from below. It is expansion in $N_{t}$ that boosts $D_{R, t}$ above the steady state throughout the transition, with a hump-shaped response. The figure is available on request.
} 
setting decision in flexible fashion. We consider two alternative assumptions: In one case, new entrants set their initial price flexibly, but taking into account that they will face a cost of price adjustment from next period on. In the other case, we simply assume that new entrants charge a constant markup over marginal cost. We show that these versions of the model deliver dynamic responses to shocks that are virtually identical to those of the benchmark model for plausible parameter values. Finally, returning to the benchmark assumption on the cost of price adjustment, we explore the implications of departing from C.E.S. preferences, extending the benchmark model to a general, homothetic specification of consumption preferences. We parametrize this specification in translog form and show that also this extension leaves the key properties of the model roughly unchanged.

\section{Entry Cost in Units of Consumption}

Our benchmark model generates reductions in firm entry in response to expansionary monetary policy shocks. This is a consequence of the increase in the entry cost evaluated in units of consumption, $w_{t} f_{E, t} / Z_{t}$, induced by the shock. The countercyclical impact response of the markup in Figure 3 is associated with a procyclical response of the real wage. This induces an increase in the cost of hiring labor for firm creation and, via the free entry condition, the price of investment, thus discouraging entry. This result conflicts with empirical evidence on the response of firm entry to monetary policy shocks in Bergin and Corsetti (2005) and Lewis (2006). Here, we present a simple modification of our benchmark model that delivers a positive response of entry to reductions in the interest rate.

The modification consists of assuming that the entry cost $f_{E, t}$, rather than being defined in units of effective labor, is defined in units of the consumption basket, $C_{t}$ : Instead of hiring labor, entry now requires purchasing a basket of materials in the amount $f_{E, t}^{C}$, where this basket has exactly the same composition as consumption, and we introduce the superscript $C$ to differentiate the notation relative to the benchmark case. As a consequence of this modification, output of the consumption sector now coincides with GDP: $Y_{t}=N_{t} \rho_{t} y_{t}=w_{t} L_{t}+N_{t} d_{t}$, and there is no longer any sectoral reallocation of labor between product creation and production of existing goods. The new assumption implies the following changes in the model of Table 1: $Y_{t}$ replaces $Y_{t}^{C}$ in the expressions for markup and profits (it is no longer necessary to have an equation defining $Y_{t}^{C}$ ), and the free entry condition equates the value of the firm to $f_{E, t}^{C}$. In log-linear terms, the New Keynesian Phillips curve is unaffected. 
The new free entry condition implies that the price of investment in new firms in units of consumption is now constant absent exogenous changes in $f_{E, t}^{C}$ due to changes in market regulation. Absent such shocks, and normalizing $f_{E, t}^{C}$ to one, the model reduces to one in which the consumption-based price of investment in firm creation is constant and equal to one unit of consumption - exactly as in the standard RBC setup without costs of capital adjustment. Importantly, this does not imply that the price of investment evaluated in data-consistent units, $v_{R, t} \equiv v_{t} / \rho_{t}$, or the nominal price of investment, $V_{t}$, are constant. But the even tighter isomorphism between our entry model and the familiar RBC framework in welfare-consistent units has important implications that we discuss below.

Abstracting from regulation changes, setting $f_{E, t}^{C}=1$, and imposing free entry, no-arbitrage between bonds and shares now implies:

$$
(1-\delta) E_{t}\left[\left(C_{t+1}\right)^{-1}\left(1+d_{t+1}\right)\right]=E_{t}\left[\left(C_{t+1}\right)^{-1} \frac{1+i_{t}}{1+\pi_{t+1}^{C}}\right]
$$

In log-linear terms, a monetary policy shock that reduces the ex ante real interest rate between $t$ and $t+1$ lowers expected profits for period $t+1$. However, it necessarily leaves the expected present discounted value of profits over the infinite future unchanged, to preserve the free entry condition $v_{t}=1$.

We log-linearize the modified model around the zero-inflation steady state. Figure 5 presents the impulse responses of the log-linearized model to a zero-persistence one-percent decrease in the interest rate under three alternative parametrizations for interest rate setting: Round markers (blue) denote the responses under the rule $\mathrm{i}_{t}=0.8 \mathrm{i}_{t-1}+0.3 \pi_{t}+\xi_{t}^{i}$, cross markers (red) denote the case $\mathrm{i}_{t}=0.8 \mathrm{i}_{t-1}+0.3 \pi_{t}+0.1 \mathrm{Y}_{R, t}+\xi_{t}^{i}$, and square markers (green) denote the case $\mathrm{i}_{t}=1.5 \pi_{t}+0.5 \mathrm{Y}_{R, t}+\xi_{t}^{i}$. In all three cases, the central bank is responding to current rather than expected inflation. By tying the equilibrium stock market price of investment in product creation to the exogenous entry cost and making the model behave exactly as the RBC framework in the investment dimension, the modified setup reintroduces the problem highlighted by Carlstrom and Fuerst (2005): If interest rate setting responds only to expected inflation, the no arbitrage condition (16) features only expected future variables, exposing the economy to indeterminacy. ${ }^{39}$ For this reason, we restrict attention to rules in which the central bank responds to current inflation, studying the consequences of interest rate smoothing and/or a response to data-consistent GDP. The responses in Figure 5 are computed for

\footnotetext{
${ }^{39}$ The link between inflation and equity prices reflected in (9) and discussed at length in the baseline model now disappears, precisely because marginal cost is no longer tied to the value of the firm.
} 
the same parameter values as the responses above, focusing on the case in which the elasticity of labor supply is $\varphi=2$. Inspection of the figure shows that the responses preserve several key features of those in Figure 3: The shock lowers the real interest rate and has expansionary consequences for consumption and GDP. The markup falls and the real wage increases. Importantly, however, the price of investment no longer rises. Even if firm profits fall, the expansion in consumption demand with unchanged firm value draws more firms into the market, and the number of entrants increases under all policy rules. ${ }^{40}$ Labor effort expands because there is no longer a contraction in the use of labor for firm creation as in Figure 3.

The response of the number of entrants is very large under the rule $\mathrm{i}_{t}=0.8 \mathrm{i}_{t-1}+0.3 \pi_{t}+$ $\xi_{t}^{i}$, with an impact expansion in investment over eighty percent above the steady state - and a correspondingly large expansion in GDP. This result is another consequence of reducing the investment side of the model to the standard RBC setup: Absent capital adjustment costs, it is a familiar result of $\mathrm{RBC}$ models that investment is excessively volatile. When the equilibrium value of the firm is tied to one, our model reproduces this result. Policy, however, plays a role: Introducing a response to GDP in interest rate setting dampens the volatility of investment and GDP, as highlighted by the responses under the rule $\mathrm{i}_{t}=0.8 \mathrm{i}_{t-1}+0.3 \pi_{t}+0.1 \mathrm{Y}_{R, t}+\xi_{t}^{i}$. Finally, the volatility of investment and GDP is further dampened by removing interest rate smoothing, thus reducing the persistence of the interest rate movement, as shown by the responses under the rule $\mathrm{i}_{t}=1.5 \pi_{t}+0.5 \mathrm{Y}_{R, t}+\xi_{t}^{i}$.

We omit the responses to productivity or deregulation shocks in this scenario (they are available on request). Importantly, under the three policy rules above and with $\varphi=2$, a positive productivity shock with persistence 0.979 now causes inflation to fall and the markup to rise on impact, as in the benchmark fixed-variety model. This happens precisely because the link between firm value and marginal cost (which was providing the extra channel generating the opposite results in our baseline model) is absent when entry requires purchasing materials. The markup moves in countercyclical fashion only under the policy rule $\mathrm{i}_{t}=0.8 \mathrm{i}_{t-1}+0.3 \pi_{t}+0.1 \mathrm{Y}_{R, t}+\xi_{t}^{i}$ because $Y_{R, t}$ falls on impact under this rule. ${ }^{41}$

To conclude, assuming that the entry cost is in the form of purchasing materials rather than hiring labor brings the predictions of the model in response to monetary policy shocks closer to

\footnotetext{
${ }^{40}$ Instead of $v_{t}$, which does not move, we report the response of $v_{R, t}$, which shows a decline in the data-consistent price of investment in response to the shock. Note that the response of $v_{t}^{E}$ coincides with that of $N_{E, t}$ since $v_{t}^{E} \equiv$ $v_{t} N_{E, t}$.

${ }^{41}$ Computing the time profile of the markup correlation with the cycle in this case results in no significant improvement relative to the benchmark model.
} 
the evidence in Bergin and Corsetti (2005) and Lewis (2006), at least qualitatively. However, precisely the feature that generates this result also has some less appealing implications: The link between monetary policy and inflation through equity prices disappears, undermining the determinacy properties that rely on this link. More generally, the crucial allocative role of movements in (welfare-consistent) firm value (the relative price of investment) disappears in this variation of the model. ${ }^{42}$ Additionally, this version of the model introduces an important asymmetry between the investment sector (creating new product varieties) and the production sector in terms of the consequences of the "love of variety" effect embedded in the definition of the consumption basket. Ceteris paribus, an increase in variety increases productivity in the investment sector while leaving that in the production sector unchanged. In the benchmark model, any changes due to the variety effect did not have such relative productivity implications. ${ }^{43}$ If we discount exogenous monetary policy shocks as a source of business cycles, these features of the modified model lead us to prefer our benchmark specification as a starting point for analysis. ${ }^{44}$

\section{Endogenous Aggregate Stickiness and Producer Entry}

So far, we assumed that new entrants are subject to the same nominal rigidity as incumbent firms. It is plausible, however, that new entrants in period $t$ will make their first price setting decision in period $t+1$ without having to pay a cost of price adjustment relative to a past price setting decision they did not make. In this case, heterogeneity in price levels arises across cohorts of firms that entered at different points in time, as their price level decisions will differ depending on the marginal cost conditions at the time of entry, thus affecting price setting decisions in subsequent periods. The degree of aggregate price rigidity in the economy becomes endogenous, as the number of new price setters that face no cost of adjusting relative to a past price decision varies with the business cycle. ${ }^{45}$

\footnotetext{
${ }^{42}$ Unless we introduce additional ad hoc costs of adjusting the number of firms along the lines of familiar costs of adjusting capital.

${ }^{43}$ To further understand this, observe that the cost of creating a new product in real units (purged of the variety effect) is $w_{R, t} f_{E, t} / Z_{t}$ in the benchmark model, where $w_{R, t} \equiv w_{t} / \rho_{t}$, and division by $\rho_{t}=\left(N_{t}\right)^{\frac{1}{\theta-1}}$ removes the pure variety effect. In the modified model, absent changes in market regulation (i.e., setting $f_{E, t}^{C}=1$ ), the cost of creating a new product purged of the variety effect is $1 / \rho_{t}$. Expansion in product variety thus lowers this cost of product creation through the pure variety effect, while $w_{R, t} f_{E, t} / Z_{t}$ is invariant to the latter.

${ }^{44} \mathrm{~A}$ further alternative specification would combine the two assumptions by positing that entry requires a CobbDouglas combination of labor and materials. The properties of responses to shocks would then depend on the relative share of these two inputs in firm creation. We leave the development of this version of the model (and the incorporation of traditional physical capital) for future work.

${ }^{45}$ Fabiani, Gattulli, and Sabbatini (2004), Gautier (2006), and Hoeberichts and Stockman (2004) find evidence of higher price flexibility in more competitive sectors of the economies they consider. To the extent that entry is more prevalent in more competitive sectors, this evidence may be suggestive of a connection between entry and price
} 
We present the extended model in the Appendix available on request. ${ }^{46}$ Prior to log-linearization, the model features an infinite number of state variables (we assume that the economy has existed since the infinite past; thus, the set of currently producing firms, $N_{t}$, includes representatives of an infinite number of entrant cohorts). However, we show that in log-linear terms, the time- $t$ price setting decisions of firms that entered in period $t-2$ and further in the past are identical. ${ }^{47}$ This allows us to characterize the log-linearized behavior of producing firms in terms of the representative members of only two sets of firms: those that are one-period old at time $t$ (and thus are taking their first price setting decision, given our assumptions on the timing of entry and production) and those who are two or more periods old.

Under the assumption that new price setters take into account that they will be subject to a cost of adjusting prices relative to their previous choice from their second period of price setting on, optimal behavior does not result in a constant markup over marginal cost in the first period of price setting, since new price setters incorporate the incentive to smooth price movements between the initial choice and next period's price implied by the expectation of future adjustment costs. For completeness of comparison, we consider also the scenario in which we assume that new price setters simply charge the constant elasticity markup $\theta /(\theta-1)$ over marginal cost.

Figure 6 presents the responses to a one percent productivity increase with persistence 0.979 for the benchmark model (blue, round markers), the model in which new entrants do not pay a cost of price adjustment but take into account future costs optimally (red, cross markers), and the model in which new entrants charge a constant markup over marginal cost (green, square markers). We keep the same parameter values as in the exercises above and we assume that labor supply is inelastic. For simplicity, we assume a policy rule in which the central bank responds with coefficient 1.5 to expected inflation in producer prices in the benchmark model. In the alternative (log-linearized) models, there are two producer price inflation rates: one that measures the change in the initial price set for time $t$ by firms that entered at $t-1$ relative to the initial choice at $t-1$ by those that entered at $t-2$, and the other measuring inflation in producer prices by older firms. However, responding to producer prices in the benchmark model amounts to responding to

stickiness. Hoffmann and Kurz-Kim (2006) analyze consumer prices in Germany over the period 1998-2003, taking into account the effect of product replacements. They report that the incidence of price changes increases when replacements are taken into account (although it is not clear that replacements are truly new products or just newly adopted products in a particular outlet).

${ }^{46}$ As a by-product, the model in the Appendix also extends Rotemberg's (1982) original model by removing the assumption of a nature-given initial price.

${ }^{47}$ We log-linearize the model around the same steady state with zero inflation in all prices as the benchmark model to facilitate the comparison of responses to shocks. 
the empirically consistent measure of consumer price inflation in the context of that model (since producer price inflation is equal to welfare-consistent consumer price inflation minus the product variety effect that is not captured by available CPI data). For this reason, we assume that in the alternative models, the central bank is responding with coefficient 1.5 to inflation in an average consumer price level $\tilde{P}_{t}$ that removes the pure product variety effect from the welfare-consistent price index $P_{t}: \tilde{P}_{t} \equiv\left(N_{t}\right)^{\frac{1}{\theta-1}} P_{t} .{ }^{48}$ Under all scenarios, the central bank is thus responding to the empirically relevant measure of expected consumer price inflation in the context of the relevant model. Figure 6 focuses on aggregate quantities, the nominal and real interest rates, inflation in the welfare consistent price index, inflation in producer prices in the benchmark model, inflation in $\tilde{P}_{t}$ (denoted $\pi_{A, t}^{C}$ ) in the alternative models, and the real wage. The responses of non-model-specific variables are virtually identical across models. In addition, the response of $\pi_{A, t}^{C}$ is virtually identical to that of $\pi_{t}$ in the benchmark model. To explore the intuition for this result, Figure 7 presents the responses of variables that are specific to cohorts of firms. For all variables other than firm values, variables indexed by a superscript 1 refer to one-period-old firms in the alternative models, and variables without superscript refer to older firms in the alternative models and the representative firm in the benchmark model. ${ }^{49}$ The response of $v_{t}$ is the response of firm value in the benchmark model. The response of $v_{t}^{t}$ is the response of the value of new entrants in the alternative models (the asset price that determines the allocation of resources to creation of firms versus production of existing goods). Although the responses point to heterogeneity of behavior across new price setters and incumbents in the extended models, the behavior of the representative firm of the benchmark model is virtually indistinguishable from that of incumbents in the alternative models - and $v_{t}$ is essentially identical to $v_{t}^{t}$. Given the assumption of a small steady-state rate of product turnover implied by $\delta=0.025$, the virtual identity of behavior across the representative firm of the benchmark model and incumbents in the alternatives implies that small departures of the number of new entrants (and new price setters) from the steady state have negligible consequences for aggregate dynamics relative to the benchmark model.

The role of $\delta$ for the differences across nominal rigidity assumptions is best illustrated by the extreme example of Figure 8. There, we present the responses of the same variables as in Figure 6

\footnotetext{
${ }^{48}$ The price index $\tilde{P}_{t}$ is closer than $P_{t}$ to empirical CPI data for the reason discussed above that data do not account for availability of new products at the frequency relevant for our model and in the form tied to our preference specification. Given any variable $X_{t}$ in units of consumption, the data-consistent counterpart in the extended models is thus defined as: $X_{R, t} \equiv P_{t} X_{t} / \tilde{P}_{t}$. See Ghironi and Melitz (2005) for further discussion.

${ }^{49}$ The inflation rate $\pi_{t}^{1}$ measures the change in the initial price set by those that entered at $t-1$ relative to those that entered at $t-2$.
} 
to a permanent decrease in the nominal interest rate with the rate of product destruction set to the unrealistically high value of $\delta=0.25$. The shock causes a permanent increase in inflation, and thus a permanent drop in the number of producers, and a permanent reallocation of labor from firm creation to production of incumbent goods. Consistent with intuition, the real consequences of the shock become smaller as we move from the benchmark model to the model in which new price setters take into account the future cost of price adjustment, and from this to the model in which new price setters charge a constant markup. This is in line with decreasing aggregate nominal rigidity as we move from one model to the next. Nevertheless, unrealistically large average product turnover (and extremely high shock persistence) are required in our model for any noticeable difference to emerge in shock transmission as a consequence of more flexible price setting behavior by new entrants.

\section{Non-C.E.S. Preferences}

Having verified that our benchmark assumption on price stickiness yields results that are robust to alternative specifications of pricing behavior by new entrants, we return to the benchmark assumption on pricing, and we study the consequences of extending the model in a different direction - allowing for non-C.E.S. preferences. Suppose the consumption basket takes a general, symmetric, homothetic form with elasticity of substitution across individual products $\theta\left(N_{t}\right)$ increasing in the number of available goods $\left(\theta^{\prime}\left(N_{t}\right)>0\right)$. This is the assumption of BGM. A derivation mirroring that for C.E.S. preferences delivers a markup equation similar to (2), with $\theta\left(N_{t}\right)$ replacing $\theta$. The only other equation from Table 1 that is affected is the one governing the variety effect, which now becomes $\rho_{t}=\rho\left(N_{t}\right)$, with elasticity $\epsilon\left(N_{t}\right) \equiv \rho^{\prime}\left(N_{t}\right) N_{t} / \rho\left(N_{t}\right)$.

We prove in the Appendix available on request that the (first-best) optimal rate of producer price inflation remains zero under this general preference specification. The same policy rule (15) as in the C.E.S case implements the optimal allocation, when combined with appropriately designed (and lump-sum-financed) fiscal instruments studied in detail in Bilbiie, Ghironi, and Melitz (2006). ${ }^{50}$ We log-linearize the markup equation for this general preference specification around the steady state with zero inflation, and parametrize preferences in the translog form introduced by Feenstra (2003) and explored by BGM (with symmetric price elasticity of demand $\left.-\left(1+\sigma N_{t}\right), \sigma>0\right)$. Assuming the calibration scheme $\theta(N)=1+\sigma N=\theta$ that ensures equality of the steady state across C.E.S.

\footnotetext{
${ }^{50}$ The (Ramsey) optimal rate of inflation would be non-zero in a second-best environment in which lump-sum instruments are unavailable. The monetary authority would trade the welfare costs of inflation against the welfare costs of markup variation coming from both a time-varying elasticity of substitution and the misalignment of the benefit of extra variety with the profit incentive provided by the markup. We leave this extension for future research.
} 
and translog preferences, we obtain the New Keynesian Phillips curve for producer price inflation under translog preferences:

$$
\pi_{t}=\beta(1-\delta) E_{t} \pi_{t+1}+\frac{\theta-1}{\kappa}\left(\mathrm{w}_{t}-\mathrm{Z}_{t}\right)-\left(\frac{1}{2 \kappa}+\frac{\theta-1}{\theta \kappa}\right) \mathrm{N}_{t}
$$

Notice the difference from the Phillips curve with C.E.S. preferences (6): The steady-state benefit of additional variety is now half of its C.E.S. counterpart and variation in the number of firms has an independent effect on the flexible-price markup via its effect on the elasticity of substitution, generating an additional effect of the number of firms on inflation.

Figure 9 shows the impulse responses to a one percent productivity increase with persistence 0.979 under C.E.S. (blue, round markers) and translog (red, cross markers) preferences for the benchmark parameter values. We assume that policy responds to expected inflation in producer prices with coefficient 1.5. Most responses are qualitatively similar across preference specifications, although quantitative differences are noticeable. The most pronounced qualitative differences are in the markup and firm-level output responses. The markup is below the steady state throughout the horizon of the response under translog preferences due to the effect of a larger number of producing firms on the elasticity of substitution. At the same time, the welfare benefit of product variety is smaller under translog preferences, and so the response of the number of producers to the shock is muted relative to the C.E.S. scenario. This dampens the response of the relative price and keeps firm-level output above the steady state throughout the transition.

To verify whether translog preferences have noticeable quantitative implications, we repeat the experiment of Table 2 under the translog specification. Table 3 replaces the model generated moments of Table 2 with the results of the flexible-price model with translog preferences (BGM Translog) and its sticky-price version. The conclusions are largely unchanged relative to Table 2 , although - consistent with what we noted above - translog preferences noticeably increase the persistence of producer price inflation: Standard deviation, autocorrelation, and correlation of $\pi_{t}$ with GDP are now $0.02,0.94$, and -0.61 , respectively. 
Table 3. Moments for: Data, BGM Translog Model, and Sticky Prices

\begin{tabular}{l|ccc|cc|ccccc|ccc}
\hline \hline Variable $X_{t}$ & \multicolumn{4}{|c|}{$\sigma_{X_{t}}$} & \multicolumn{3}{|c|}{$\sigma_{X_{t}} / \sigma_{Y_{R, t}}$} & \multicolumn{3}{c|}{$E\left[X_{t} X_{t-1}\right]$} & \multicolumn{3}{c}{$\operatorname{corr}\left(X_{t}, Y_{R, t}\right)$} \\
\hline$Y_{R, t}$ & $\mathbf{1 . 8 1}$ & 1.25 & 1.29 & $\mathbf{1 . 0 0}$ & & $\mathbf{0 . 8 4}$ & 0.70 & 0.70 & $\mathbf{1 . 0 0}$ & \\
\hline$C_{R, t}$ & $\mathbf{1 . 3 5}$ & 0.75 & 0.81 & $\mathbf{0 . 7 4}$ & 0.60 & 0.63 & $\mathbf{0 . 8 0}$ & 0.78 & 0.74 & $\mathbf{0 . 8 8}$ & 0.95 & 0.98 \\
\hline Investment, $v_{R, t} N_{E, t}$ & $\mathbf{5 . 3 0}$ & 4.27 & 4.01 & $\mathbf{2 . 9 3}$ & 3.42 & 3.11 & $\mathbf{0 . 8 7}$ & 0.66 & 0.69 & $\mathbf{0 . 8 0}$ & 0.96 & 0.98 \\
\hline$L_{t}$ & $\mathbf{1 . 7 9}$ & 0.49 & 0.49 & $\mathbf{0 . 9 9}$ & 0.39 & 0.38 & $\mathbf{0 . 8 8}$ & 0.66 & 0.68 & $\mathbf{0 . 8 8}$ & 0.95 & 0.97 \\
\hline
\end{tabular}

Source for data moments: King and Rebelo (1999)

Finally, Figure 10 augments Figure 4 by including the model-based markup cyclicality in the translog model with sticky prices. Introducing translog preferences shifts the correlation between markup and GDP at leads and lags in the "right" direction through the effect of variation in the number of producers on the elasticity of substitution. However, the contemporaneous correlation becomes even more excessively negative. The flexible-price translog model remains the best (among those we considered) at reproducing the cyclicality of the markup. ${ }^{51}$

\section{Conclusions}

This paper studied the implications of introducing endogenous product creation in a sticky-price model of the business cycle suitable for monetary policy analysis. When variety is endogenous and the price setting distortion pertains to individual producer prices, first-best optimal monetary policy should aim at stabilizing product price inflation and let the welfare-relevant consumer price index fluctuate to accommodate changes in the number of products. Our model highlights a novel motive for price stability, which occurs because inflation acts as a distortionary tax on firm profits, and profits provide incentives to firms for product creation.

Our model also identifies a new channel for monetary policy transmission through the price of equity (the value of a firm, or product). This price is featured in the inflation dynamics equation in a way that is absent from standard fixed-variety models, precisely due to the connection between the markup (and marginal cost) and the price of equity via the free entry condition. Moreover, since our model embeds a portfolio decision between holding equity and bonds, monetary policy influences the price of equity through a no-arbitrage condition that relates the real return on bonds

\footnotetext{
${ }^{51}$ Not surprisingly, lowering the value of the nominal rigidity parameter $\kappa$ below Ireland's (2001) estimate improves the performance of the sticky-price translog model in terms of markup cyclicality at leads and lags. However, the contemporaneous correlation with GDP remains excessively negative $(-0.81)$ even with $\kappa$ as low as 5 .
} 
(which the central bank influences) to the expected real return on equity. This link between inflation dynamics and monetary policy through assets prices is central to the validity of the Taylor Principle in our endogenous-variety model with capital accumulation in the form of new production lines. This is unlike results from fixed-variety models with physical capital.

Endogenous product variety has implications for inflation dynamics and the estimation of New Keynesian Phillips curve equations. Empirical proxies for (unobservable) markups need to be amended in order to estimate Phillips curves in the presence of product creation. Moreover, we show that the Phillips curve in the presence of endogenous variety features an extra term (with respect to its fixed-variety counterpart) that depends on the number of available varieties, a state variable. This goes in the direction of alleviating the notorious difficulty of New Keynesian models in accounting for inflation persistence with forward-looking price-setting. Finally, we identify an 'endogeneity bias' that is present whenever estimates of the Phillips curve ignore product variety and hence attribute the endogenous component coming from its impact on inflation dynamics to exogenous 'cost-push' shocks.

Numerical exercises show that the sticky-price model performs similarly to the flexible-price counterpart in terms of matching several features of the U.S. business cycle given a policy specification that is plausible for inflation-sensitive policymakers. Consistent with the presence of an endogenous state variable in the Phillips curve, the model generates fairly persistent inflation dynamics. These results are confirmed by two extensions of the benchmark setup, studying alternative assumptions for the initial price setting decision by new entrants and the consequences of non-C.E.S. (specifically, translog) preferences. Another extension studies a version of the model in which entry requires purchasing materials rather than hiring labor. In that model, the link between firm value and marginal production cost implied by free entry disappears: Monetary expansions induce an increase in entry, but technology shocks generate procyclical markups and immediate deflation for a wider range of parameter values.

Recent empirical literature has documented the pervasiveness of product creation and destruction at a frequency that is relevant for business cycle propagation. This paper provides a starting point for incorporation of this phenomenon in monetary models of the business cycle suitable for policy analysis. Like the benchmark New Keynesian model with fixed product variety, the benchmark model of this paper has shortcomings from an empirical, quantitative perspective. Combined with the procyclical response of entry to productivity shocks, price stickiness induces excessive countercyclicality of markups relative to the data. However, the model highlights realistic conse- 
quences of product creation subject to sunk costs (persistence), a new motive for price stability, and a new connection between monetary policy and equity prices that is not featured in the previous New Keynesian literature. The ability of the model to generate procyclical producer entry and profits (even in the presence of such countercyclical markups) significantly improves on the New Keynesian benchmark with respect to these stylized facts. Quantitative extensions to address remaining empirical shortcomings - for instance, the introduction of congestion effects in entry that would dampen the procyclicality of real wages and the countercyclicality of markups - would be easy to pursue. ${ }^{52}$ Thus, we view the model of this paper as a promising stepping stone for future research on a variety of positive and normative questions in potentially richer, monetary models with endogenous producer entry.

\section{References}

[1] Ambler, S., and E. Cardia (1998): "The Cyclical Behaviour of Wages and Profits under Imperfect Competition," Canadian Journal of Economics 31: 148-164.

[2] Axarloglou, K. (2003): "The Cyclicality of New Product Introductions," Journal of Business 76: $29-48$.

[3] Basu, S., and M. S. Kimball (1997): "Cyclical Productivity with Unobserved Input Variation," NBER WP 5915.

[4] Berentsen, A., and C. Waller (2007): "Optimal Stabilization with Endogenous Firm Entry," manuscript, University of Basel and University of Notre Dame.

[5] Bergin, P. R., and G. Corsetti (2005): "Towards a Theory of Firm Entry and Stabilization Policy," NBER WP 11821.

[6] Bernard, A. B., J. Eaton, J. B. Jensen, and S. Kortum (2003): "Plants and Productivity in International Trade," American Economic Review 93: 1268-1290.

[7] Bernard, A. B., S. J. Redding, and P. K. Schott (2006): "Multi-Product Firms and Product Switching," NBER WP 12293.

[8] Bilbiie, F. O., F. Ghironi, and M. J. Melitz (2005): "Endogenous Entry, Product Variety, and Business Cycles," manuscript, University of Oxford, Boston College, and Princeton University.

\footnotetext{
${ }^{52}$ Congestion effects would also dampen the positive response of entry to monetary expansions when entry requires materials.
} 
[9] Bilbiie, F. O., F. Ghironi, and M. J. Melitz (2006): "Monopoly Power and Endogenous Variety in Dynamic Stochastic General Equilibrium: Distortions and Remedies," manuscript, University of Oxford, Boston College, and Princeton University.

[10] Broda, C. (2004): "CPI Biases and their Impact on Policy", International Perspectives 32, Federal Reserve Bank of New York.

[11] Broda, C., and D. E. Weinstein (2006): "Globalization and the Gains from Variety," Quarterly Journal of Economics 121: 541-585.

[12] Broda, C., and D. E. Weinstein (2007): "Product Creation and Destruction: Evidence and Price Implications," manuscript, University of Chicago and Columbia University.

[13] Calvo, G. A. (1983): "Staggered Prices in a Utility Maximizing Framework," Journal of Monetary Economics 12: 983-998.

[14] Campbell, J. R. (1998): "Entry, Exit, Embodied Technology, and Business Cycles," Review of Economic Dynamics 1: 371-408.

[15] Carlstrom, C. T., and T. S. Fuerst (2005): "Investment and Interest Rate Policy: A Discrete Time Analysis," Journal of Economic Theory 123: 4-20.

[16] Chatterjee, S., and R. Cooper (1993): "Entry and Exit, Product Variety and the Business Cycle," NBER WP 4562.

[17] Christiano, L. J., M. S. Eichenbaum, and C. L. Evans (1999): "Monetary Policy Shocks: What Have We Learned and to What End?" in Taylor, J. B., and M. Woodford, eds., Handbook of Macroeconomics, vol. 1B, 65-148, Elsevier, Amsterdam

[18] Clarida, R., J. Galí, and M. Gertler (1999): “The Science of Monetary Policy: A New Keynesian Perspective," Journal of Economic Literature 37: 1661-1707.

[19] Clarida, R., J. Galí, and M. Gertler (2000): "Monetary Policy Rules and Macroeconomic Stability: Evidence and Some Theory," Quarterly Journal of Economics 115: 147-180.

[20] Comin, D., and M. Gertler (2006): "Medium Term Business Cycles," American Economic Review 96: 523-551. 
[21] Cook, D., (2001): "Time to Enter and Business Cycles," Journal of Economic Dynamics and Control 25: 1241-1261.

[22] Devereux, M. B., A. C. Head, and B. J. Lapham (1996a): "Aggregate Fluctuations with Increasing Returns to Specialization and Scale," Journal of Economic Dynamics and Control 20: $627-656$.

[23] Devereux, M. B., A. C. Head, and B. J. Lapham (1996b): "Monopolistic Competition, Increasing Returns, and the Effects of Government Spending," Journal of Money, Credit, and Banking 28: 233-254.

[24] Dixit, A. K., and J. E. Stiglitz (1977): "Monopolistic Competition and Optimum Product Diversity," American Economic Review 67: 297-308.

[25] Dupor, W. D. (2001): "Investment and Interest Rate Policy," Journal of Economic Theory 98: 85-113.

[26] Elkhoury, M., and T. Mancini Griffoli (2006): "Monetary Policy with Firm Entry," manuscript, Graduate Institute of International Studies, Geneva.

[27] Erceg, C. J., L. Guerrieri, and C. Gust (2005): "Expansionary Fiscal Shocks and the U.S. Trade Deficit," International Finance 8: 363-397.

[28] Fabiani, S., Gattulli, A., and R. Sabbatini (2004): "The Pricing Behaviour of Italian Firms: New Survey Evidence on Price Stickiness," ECB WP 333.

[29] Feenstra, R. C. (2003): "A Homothetic Utility Function for Monopolistic Competition Models, without Constant Price Elasticity," Economics Letters 78: 79-86.

[30] Fuhrer, J. C., and G. Moore (1995): "Inflation Persistence," Quarterly Journal of Economics 110: $127-159$.

[31] Galí, J., and M. Gertler (1999): "Inflation Dynamics: A Structural Econometric Analysis," Journal of Monetary Economics 44: 195-222.

[32] Gautier, E. (2006): "The Behaviour of Producer Prices: Some Evidence from French PPI Data," ECB WP 699. 
[33] Ghironi, F., and M. J. Melitz (2005): "International Trade and Macroeconomic Dynamics with Heterogeneous Firms," Quarterly Journal of Economics 120: 865-915.

[34] Hoeberichts, M. M., and A. Stockman (2004): "Pricing Behavior of Dutch Companies: Main Results from a Survey," manuscript, De Nederlandsche Bank.

[35] Hoffmann, J., and J.-R. Kurz-Kim (2006): "Consumer Price Adjustment under the Microscope: Germany in a Period of Low Inflation," Discussion Paper 16/2006, Deutsche Bundesbank.

[36] Ireland, P. (2001): "Sticky-Price Models of the Business Cycle: Specification and Stability," Journal of Monetary Economics 47: 3-18.

[37] Jaimovich, N. (2004): "Firm Dynamics, Markup Variations, and the Business Cycle," manuscript, University of California, San Diego.

[38] Jovanovic, B. (2006): "Investment Options and the Business Cycle", manuscript, New York University.

[39] Kerr, W., and R. King (1996): "Limits on Interest Rate Rules in the IS-LM Model," Federal Reserve Bank of Richmond Economic Quarterly, Spring.

[40] King, R. G., and S. T. Rebelo (1999): "Resuscitating Real Business Cycles," in Taylor, J. B., and M. Woodford, eds., Handbook of Macroeconomics, vol. 1B, 927-1007, Elsevier, Amsterdam.

[41] Lagos, R., and R. Wright (2005): "A Unified Framework for Monetary Theory and Policy Evaluation," Journal of Political Economy 113: 463-484.

[42] Laxton, D., and P. Pesenti (2003): "Monetary Rules for Small, Open, Emerging Economies," Journal of Monetary Economics 50: 1109-1146.

[43] Leeper, E. M. (1991): "Equilibria under 'Active' and 'Passive' Monetary and Fiscal Policies," Journal of Monetary Economics 27: 129-147.

[44] Leeper, E. M., C. A. Sims, and T. Zha (1996): "What Does Monetary Policy Do?" Brookings Papers on Economic Activity 2: 1-63

[45] Lewis, V. (2006): "Macroeconomic Fluctuations and Firm Entry: Theory and Evidence," manuscript, Catholic University Leuven. 
[46] Rotemberg, J. J. (1982): “Monopolistic Price Adjustment and Aggregate Output," Review of Economic Studies 49: 517-531.

[47] Rotemberg, J. J., and M. Woodford (1992): "Oligopolistic Pricing and the Effects of Aggregate Demand on Economic Activity," Journal of Political Economy 100: 1153-1207.

[48] Rotemberg, J. J., and M. Woodford (1995): "Dynamic General Equilibrium Models and Imperfect Product Markets," in Cooley, T. F., ed., Frontiers of Business Cycle Research, Princeton University Press, Princeton.

[49] Rotemberg, J. J., and M. Woodford (1999): "The Cyclical Behavior of Prices and Costs," in Taylor, J. B., and M. Woodford, eds., Handbook of Macroeconomics, vol. 1B, 1051-1135, Elsevier, Amsterdam.

[50] Sbordone, A. (2002): "Prices and Unit Labor Costs: A New Test of Price Stickiness," Journal of Monetary Economics 49: 265-292.

[51] Stebunovs, V. (2006): "Finance as a Barrier to Entry in Dynamic Stochastic General Equilibrium," Ph.D. Dissertation, Boston College.

[52] Woodford, M. (2003): Interest and Prices: Foundations of a Theory of Monetary Policy, Princeton University Press, Princeton.

[53] Yun, T. (1996): "Nominal Price Rigidity, Money Supply Endogeneity, and Business Cycles," Journal of Monetary Economics 37: 345-370. 

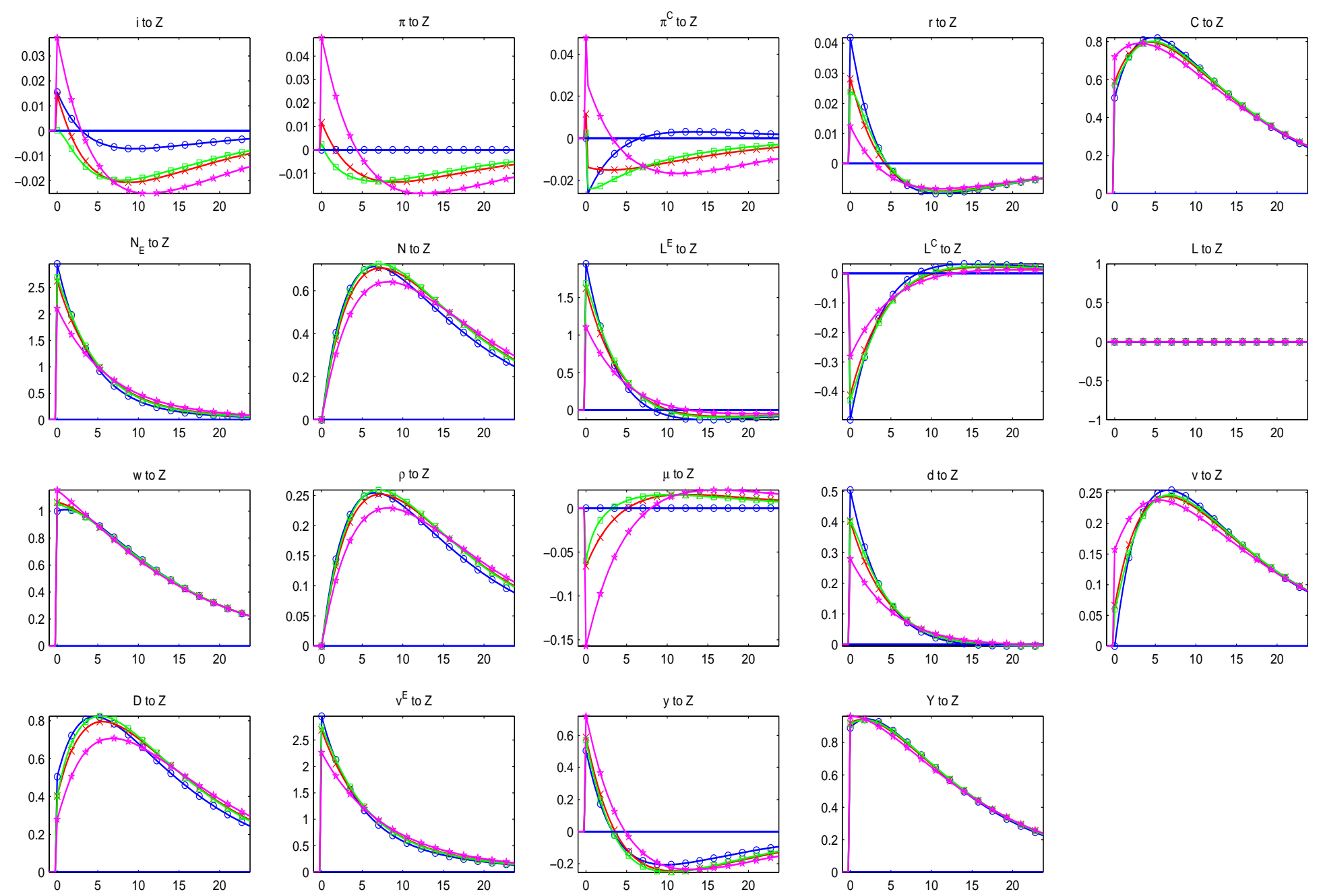

Figure 1. Impulse Responses: Productivity Shock, Persistence $.979^{*}$

*Round markers (blue): Optimal policy; Cross markers (red): $\mathrm{i}_{t}=1.5 E_{t} \pi_{t+1}$; Square markers (green): $\mathrm{i}_{t}=.8 \mathrm{i}_{t-1}+.3 E_{t} \pi_{t+1}$; Star markers (pink): $\mathrm{i}_{t}=1.5 E_{t} \pi^{C}{ }_{t+1}$. 

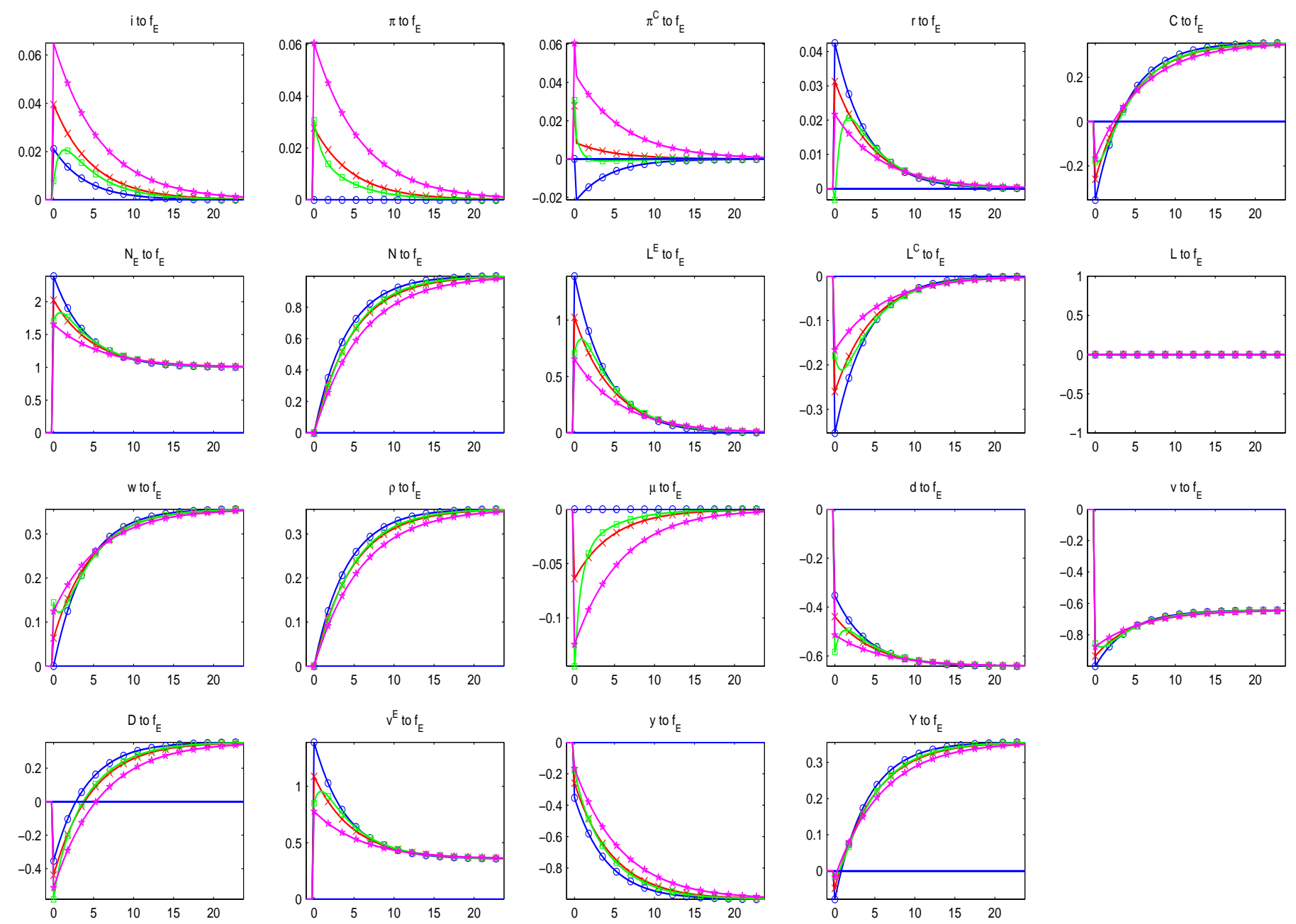

Figure 2. Impulse Responses: Permanent Deregulation ${ }^{*}$

*Round markers (blue): Optimal policy; Cross markers (red): $\mathrm{i}_{t}=1.5 E_{t} \pi_{t+1}$; Square markers (green): $\mathrm{i}_{t}=.8 \mathrm{i}_{t-1}+.3 E_{t} \pi_{t+1} ;$ Star markers (pink): $\mathrm{i}_{t}=1.5 E_{t} \pi^{C}{ }_{t+1}$. 

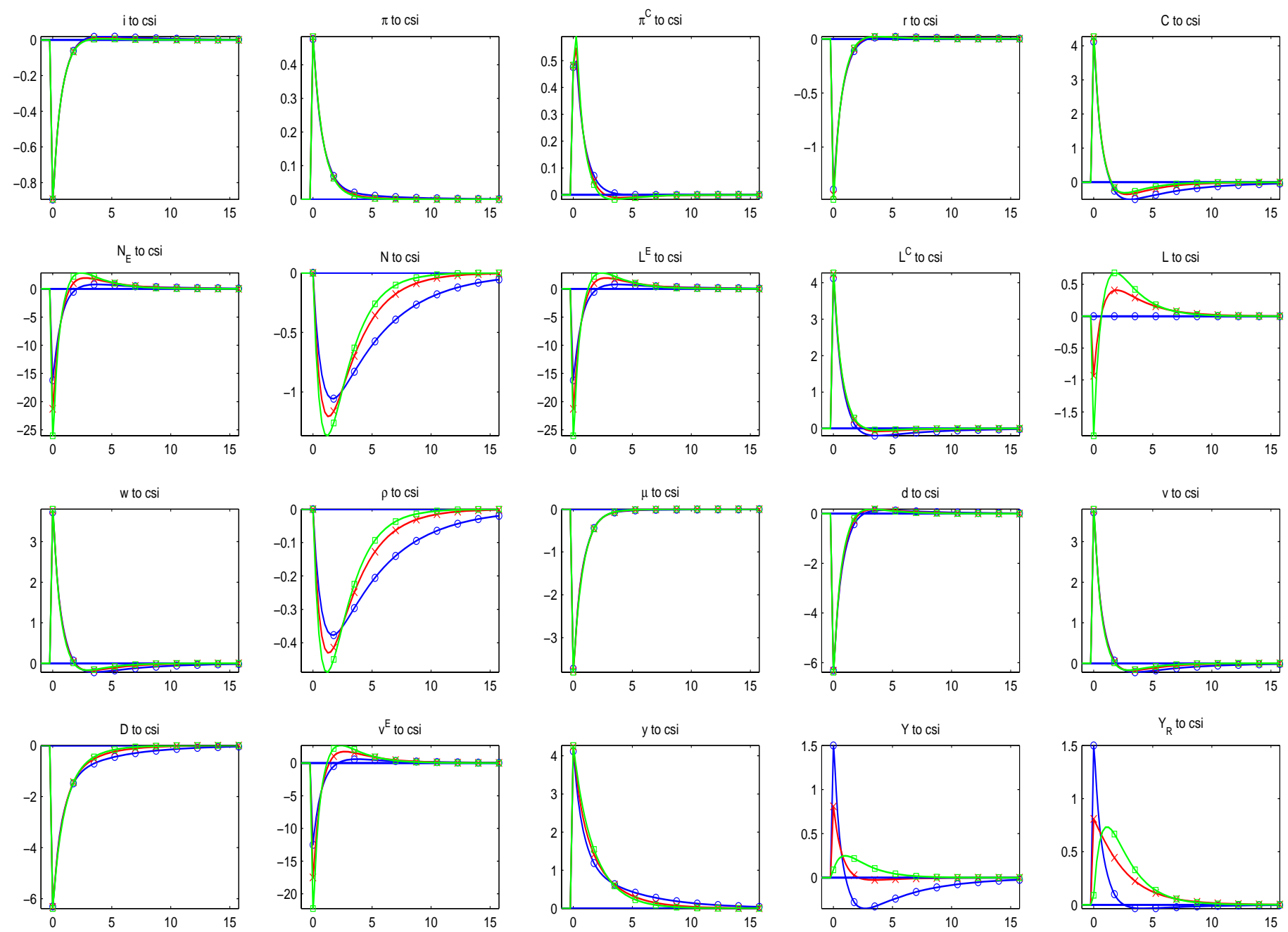

Figure 3. Impulse Responses: Interest Rate Shock, Persistence 0*

*Round markers (blue): Inelastic labor; Cross markers (red): Labor supply elasticity = 2; Square markers (green): Labor supply elasticity $=4$. 


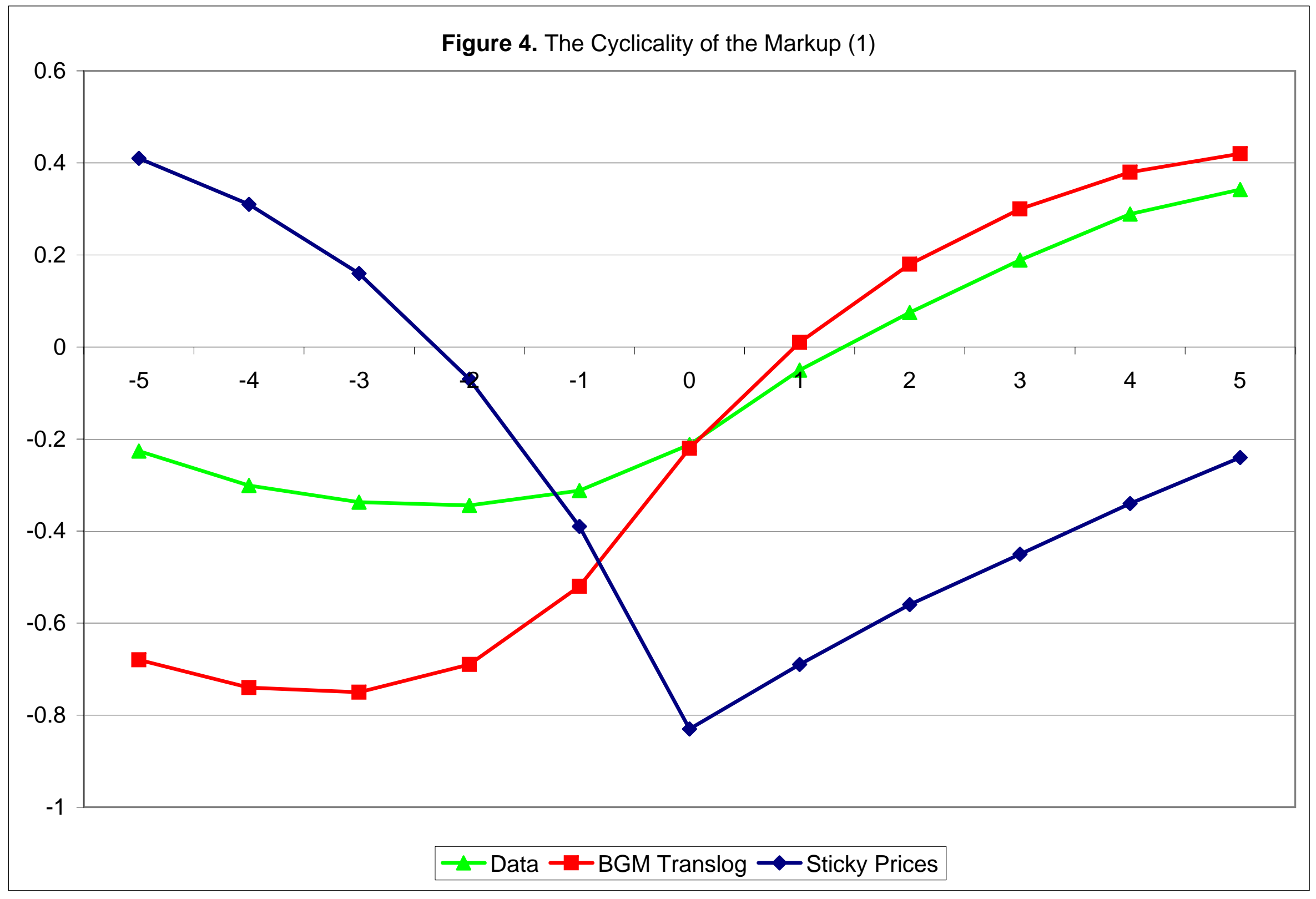


i to csi
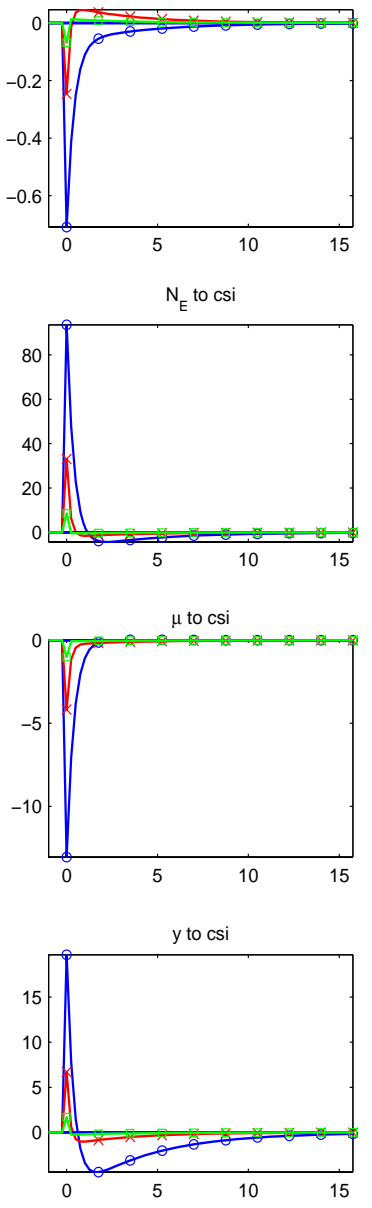

$\pi$ to cs

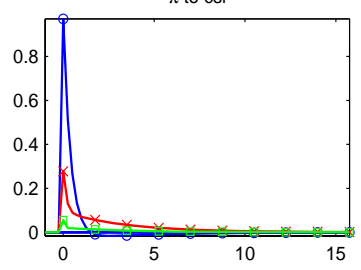

$\mathrm{N}$ to csi

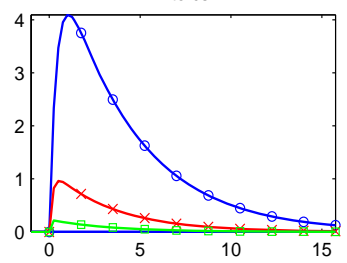

$d$ to csi
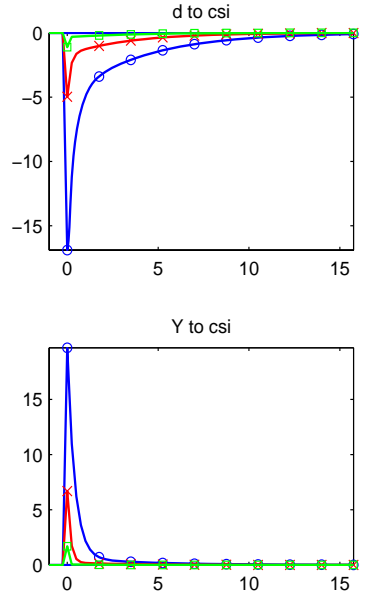

$\pi^{C}$ to csi

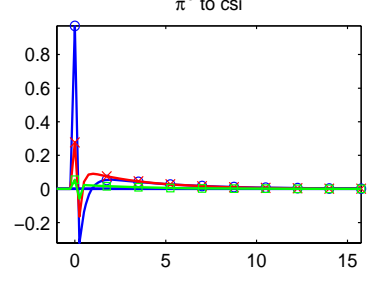

L to csi

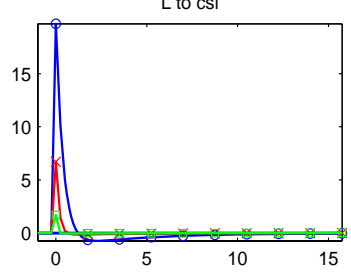

$v_{B}$ to csi

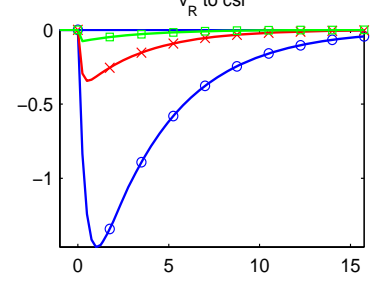

$\mathrm{Y}_{\mathrm{R}}$ to csi

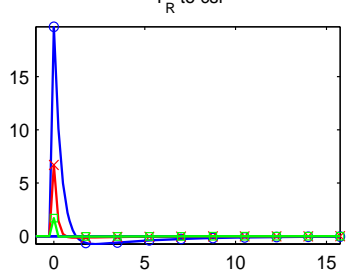

C to cs

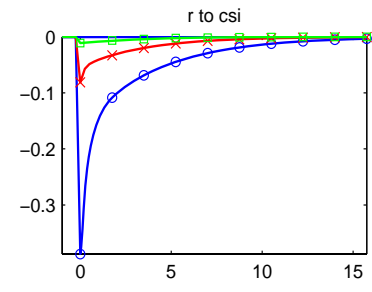

w to csi

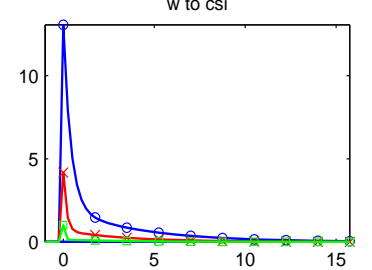

to $c$ i
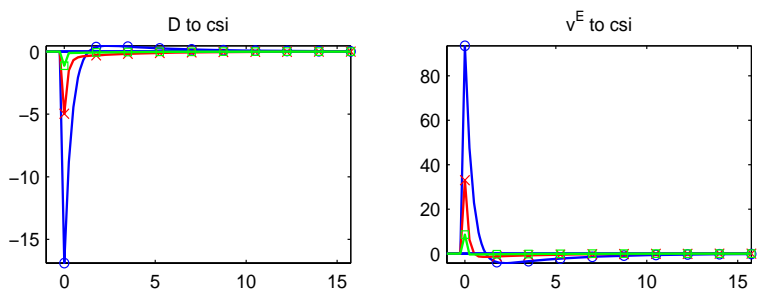

Figure 5. Impulse Responses: Interest Rate Shock, Persistence 0, Entry Cost in Units of Consumption*

*Round markers (blue): $\mathrm{i}_{t}=.8 \mathrm{i}_{t-1}+.3 \pi_{t}$; Cross markers (red): $\mathrm{i}_{t}=.8 \mathrm{i}_{t-1}+.3 \pi_{t}+.1 \mathrm{Y}_{R, t} ;$ Square markers (green): $\mathrm{i}_{t}=1.5 \pi_{t}+.5 \mathrm{Y}_{R, t}$. 

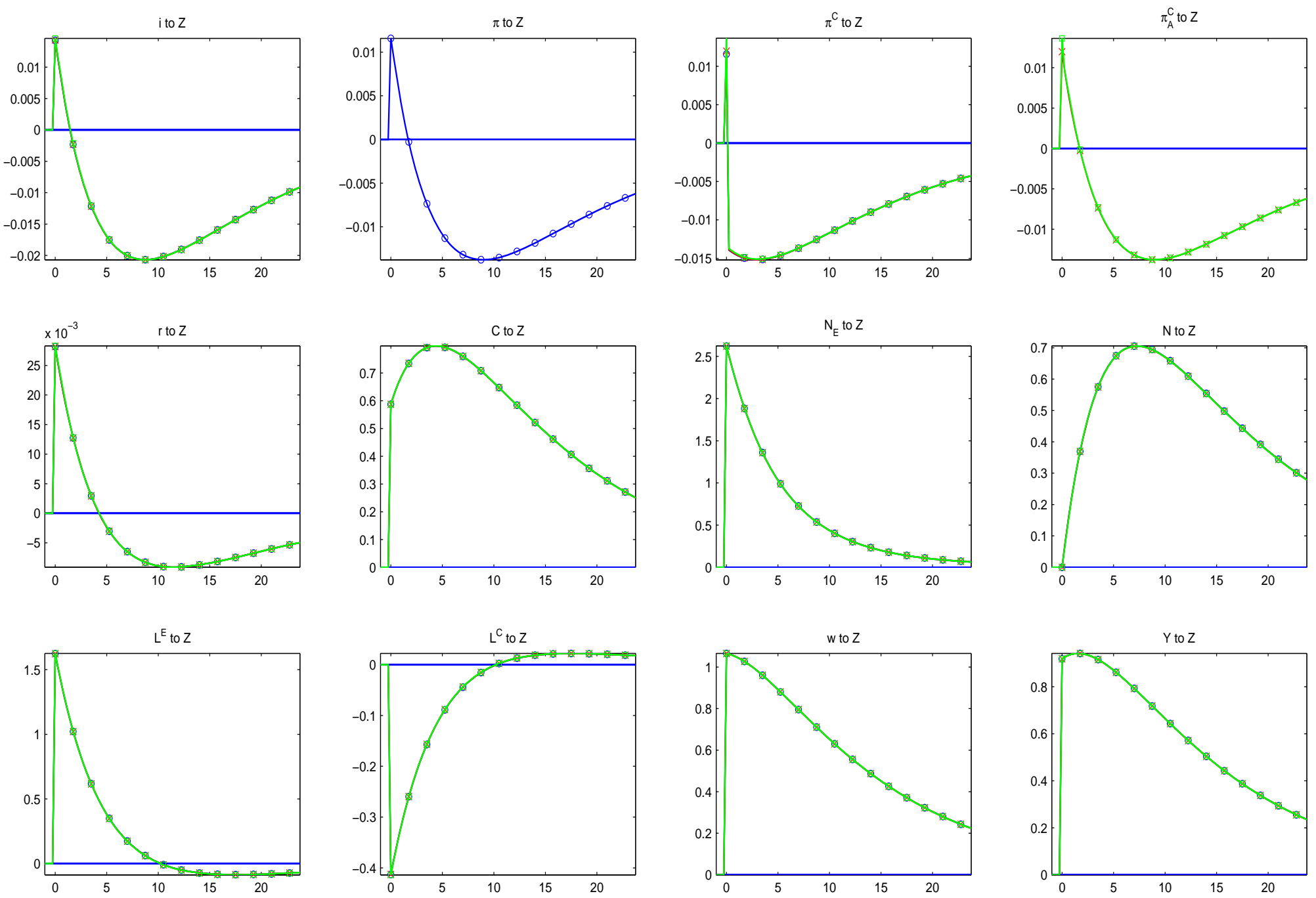

Figure 6. Alternative Assumptions on Initial Price Setting: Impulse Responses to a Productivity Shock, Aggregate Variables*

*Round markers (blue): Benchmark; Cross markers (red): Entrants take future cost into account; Square markers (green): Entrants charge constant markups. 

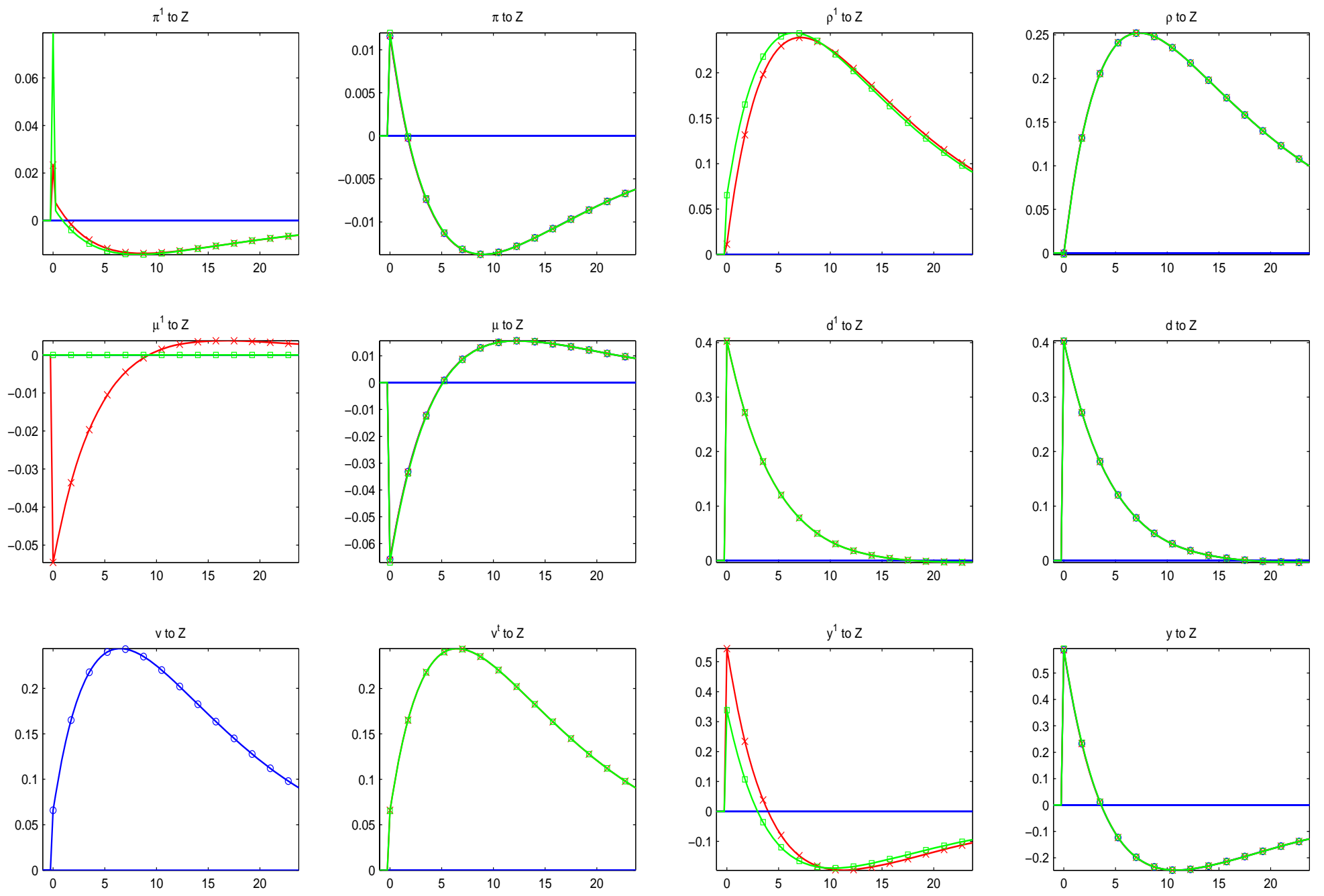

Figure 7. Alternative Assumptions on Initial Price Setting: Impulse Responses to a Productivity Shock, Firm-Level Variables*

*Round markers (blue): Benchmark; Cross markers (red): Entrants take future cost into account; Square markers (green): Entrants charge constant markups. 

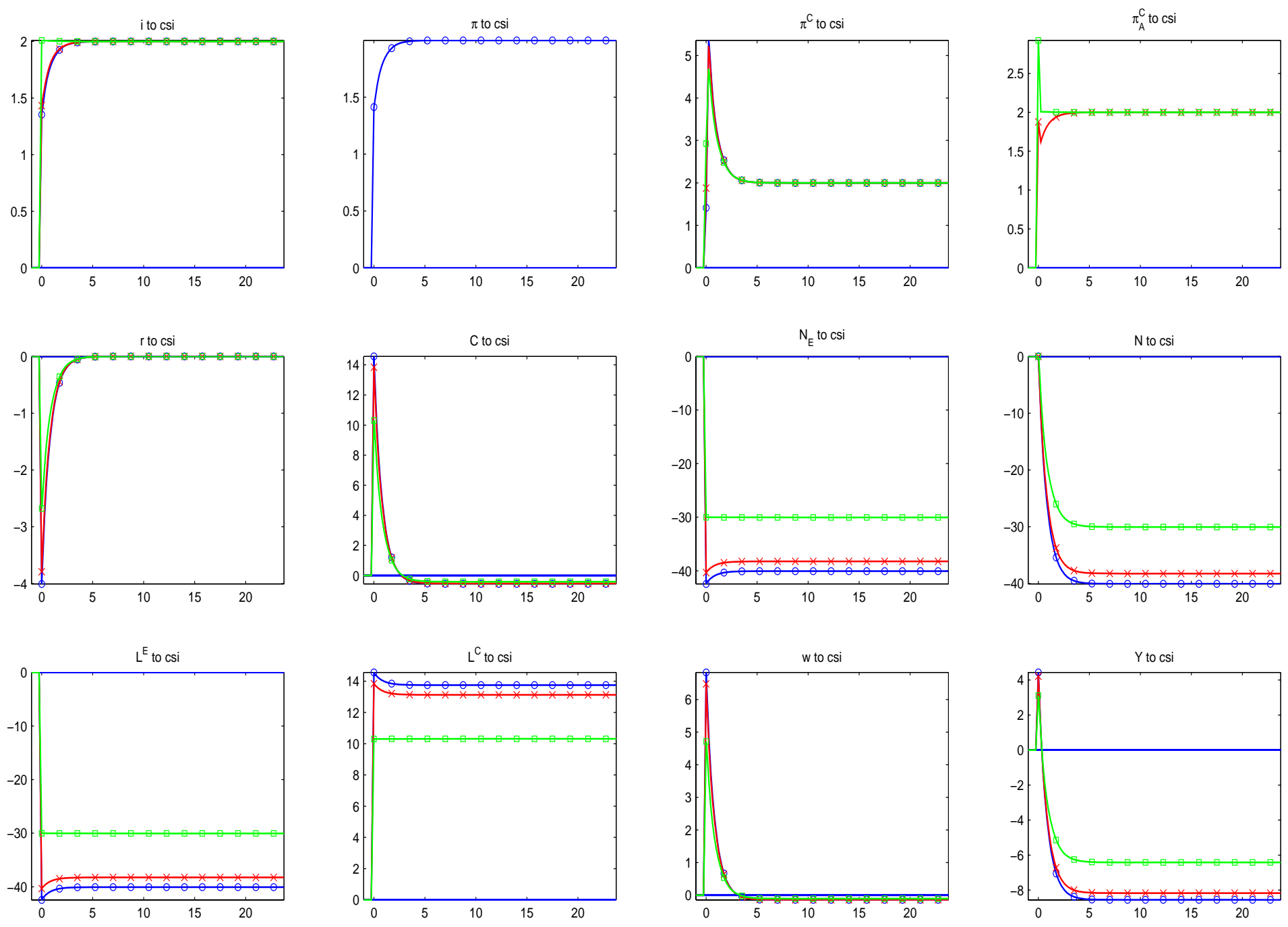

Figure 8. Alternative Assumptions on Initial Price Setting: Impulse Responses to a Permanent Interest Rate Shock*

*Round markers (blue): Benchmark; Cross markers (red): Entrants take future cost into account; Square markers (green): Entrants charge constant markups. 

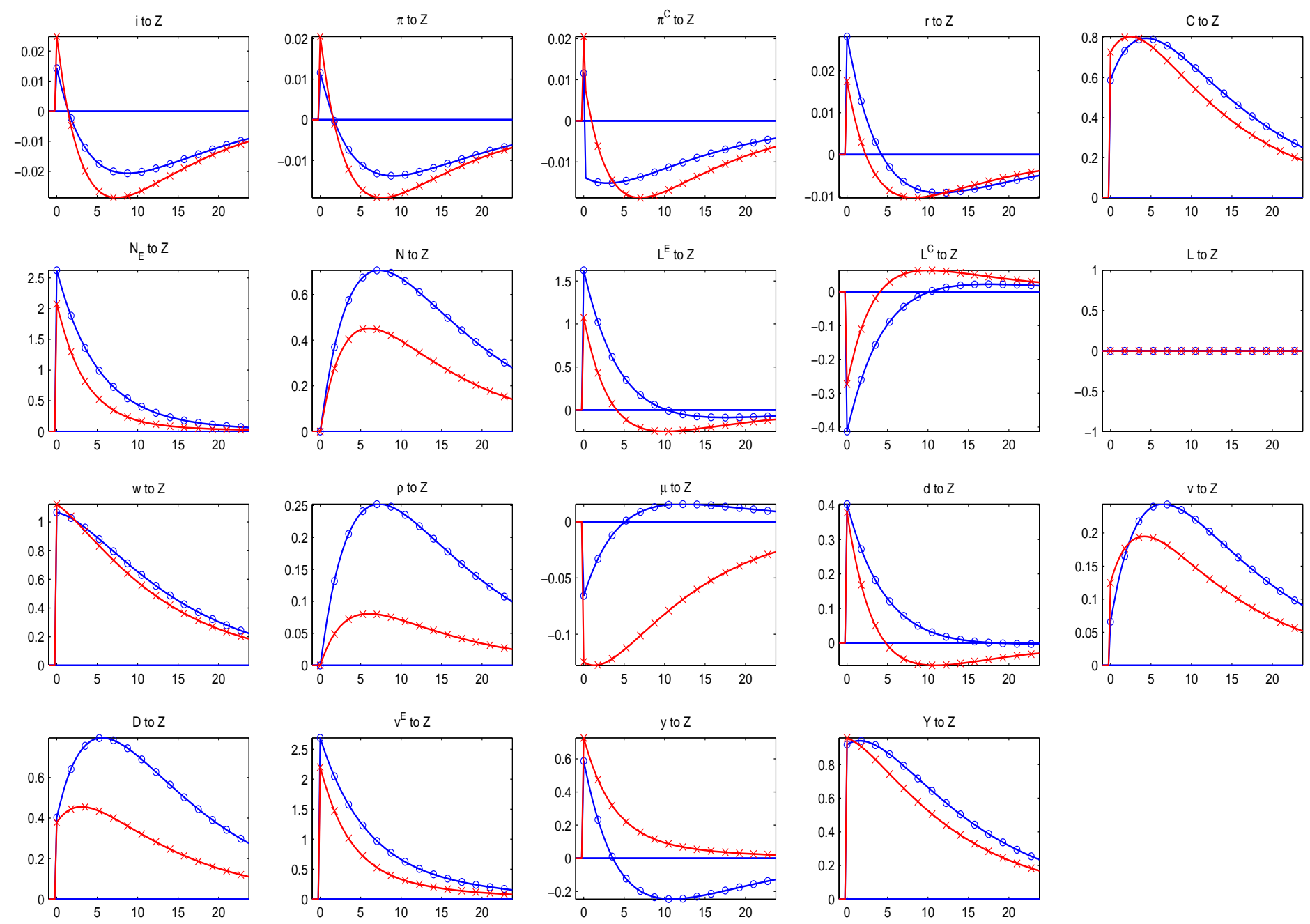

Figure 9. C.E.S. v.s. Translog: Impulse Responses to a Productivity Shock, Persistence $.979^{*}$

*Round markers (blue): C.E.S.; Cross markers (red): Translog; Policy: $\mathrm{i}_{t}=1.5 E_{t} \pi_{t+1}$. 


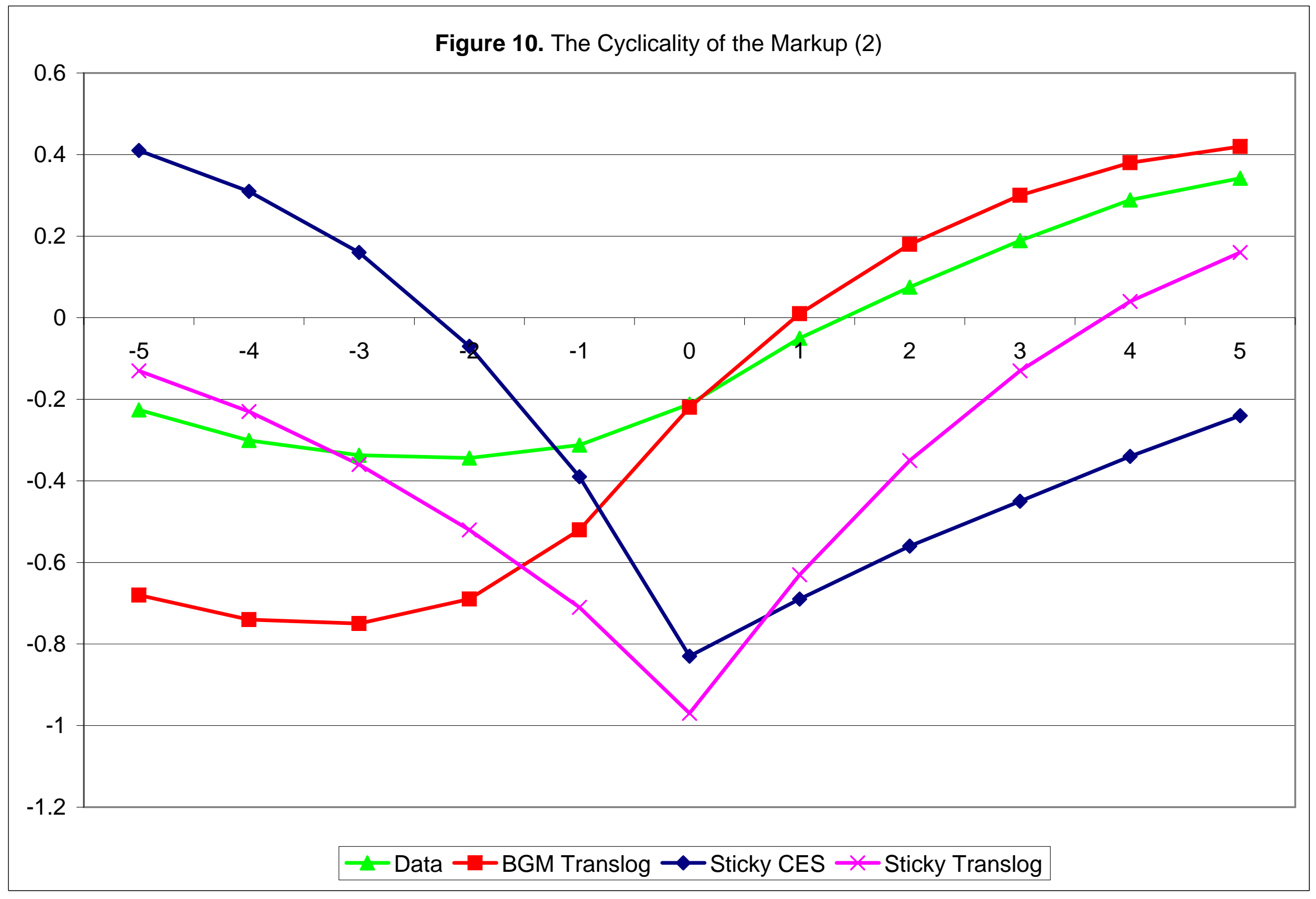

